$\frac{151 / 26 / 29}{2 / 2}$ LA-7935-MS

Informal Report
DR. $T 1$

\title{
A Parametric Study of the Tormac Fusion Reactor Concept
}




\section{MASTER}

LA-7935-MS

Informal Report

UC-20d

Issued: August 1979

\section{A Parametric Study of the \\ Tormac Fusion Reactor Concept}

R. L. Miller

R. A. Krakowski

C. G. Bathke

This teport was prepared as an account of work

Govemment. Neilhet the

Uniced States nor the Lufited Slates Depalment of

Energy, nor any of their empioyees, nor any of their

contraclors, subcontractors, or their employees, makes

any warranty, express or implied, or atsumes any legal

liability or sesponsibuliny for the accuracy, cornplete ness

or usefulness of any informalion, apparazus, paoduct or

process disclused, or gepresents that its use would not

process disclused, or sepresents
infringe privately owned rights.

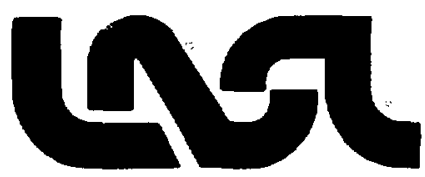


CONTENTS

ABSTRACT

I. INTRODUCTION

II. EXECUTIVE SUMMARY

III. THE TORMAC REACTOR CONCEPT

A. Description of Reactor Core

B. Description of Reactor Operation

C. Tormac Reactor Power-Balance Model

1. Overal1 Model and Design Basts

2. Formulation of Tormac Reactor Power Balance

a. Cusp Confinement T1me

b. Bremsstrahlung Radiation Loss

c. Cyclotron Radiation Loss

d. Fusion Neutron Power

e. Alpha-Particle Power

f. Englneering Q-Value and Net Power 20

g. Wall-Loading Constraints 22

D. Evaluation of Reactor Model 23

1. Parametric Study 23

2. Sensitivity to Tormac Confinement 26

3. Reactor Magnetics Implications 30

4. Representative Operating Points 32

IV. CONCLUSIONS AND EVALUATION

V. APPENDIX: MAGNETICS DESIGN 37

A. Calculational Procedure $\quad 37$

B. Calculational Mode 1

C. Results of Minimum-B Search 45

D. Estimate of Tormac Reactor Configuration 54 
A Parametric Study of the Tormac Fusion Reactor Concept

R. L. Miller, R. A. Krakowsk1, and C. G. Bathke

Abstract

A preliminary but comprehensive power balance for the D-T Tormac magnetic fusion reactor concept is examined parametrically in order to establish general scaling relationships, tradeoffs, and constraints. The results are based on the simplifying assumptions of steady-state operation, a homogeneous plasma, and ideal thin-sheath, mirror-like confinement. Crucial physics uncertainties requiring further theoretical and experimental research attention are identified. Representative reactor physics operating points are generated to illustrate anticipated Tormac reactor embodiments. This study should be considered preliminary to a more detailed physics and technology modeling effort and is intended only to scope and identify possible operating points, parametric sensitivites, and potential physics/technological problems.

\section{INTRODUCTION}

As part of an overall program for assessing the reactor potential of a number of alternative magnetic fusion concepts, the Office of Fusion Energy, US Department of Energy, has funded systems studies according to a three tier structure. These studies are catergorized in order of decreasing level of effort and detail as Level I, Level II, and Level III. The highest level of study (Level I) would include in a multi-man-year effort considerable conceptual design and economics analysis, in addition to sophisticated, state-of-the-art physics and operating-point analyses. The lowest level of study (Level III) would characterize less understood and developed confinement schemes by means of relatively simple physics models and parametric analysis of potential reactor operating points. Generally, a Level III study would not provide a reactor embodiment per se, and, because of obvious gaps in the physics understanding of these relatively unexplored concepts, only a range of potential reactor operating points may be parametrically identified. The Tormac study described herein is a Level III study. 
The essential features of the Tormac (Toroidal Magnetic Cusp) approach to the magnetic confinement of thermonuclear fusion plasmas have been known for many years. ${ }^{-3}$ Figure 1 Iliustrates schematicaliy the Tormac plasma/field configuration. The main (bulk) plasma is confined in a toroidal region of closed flux surfaces similar to a tokamak configuration. Completely surrounding this bulk toroidal plasma is a layer (sheath) of plasma confined on open magnettc field lines, containing both poloidal and toroldal field comporents; these open field lines lead eventually to the walls of the system or to a plasma dump. The Tormac, therefore, is a toroidal stuffed cusp. The open-field-line region would provide an absolute minimum-B magnetic well. Plasma on the open field lines is contained by "bouncing" or mirroring back and forth between field maxima located somewhere between the line cusps and the plasma dump (Fig. 1). The sheath plasma is subject to loss by scattering collisions into the phase-space mirror loss cones. A steady-state particle flow balance requires that this sheath loss rate be offset by diffusive flow of plasma across the toroidal bias field from the bulk plasma into the sheath.

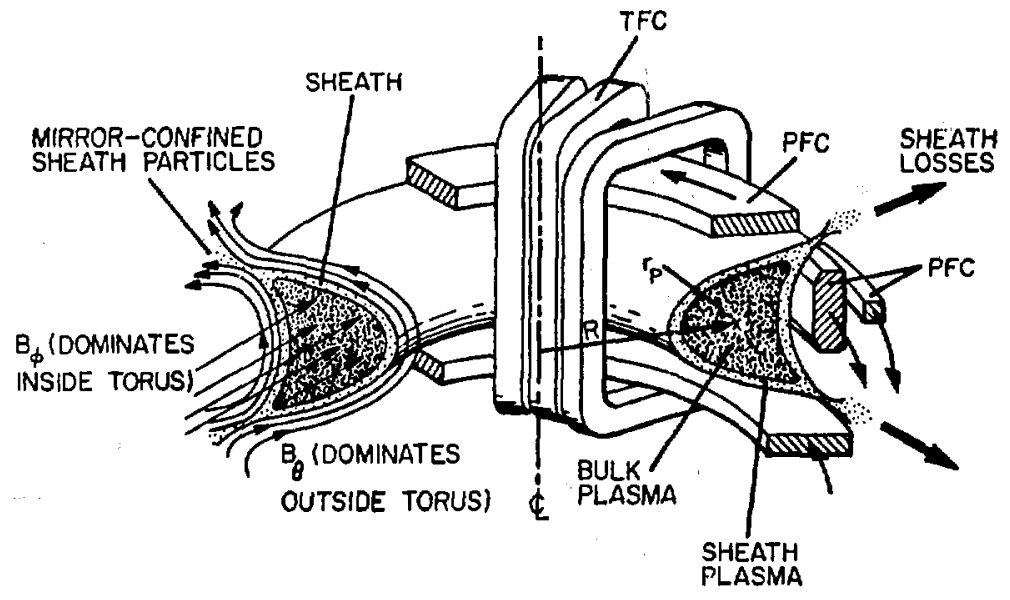

Fig. 1. Schematic representation of the Tormac (Toroidal Magnetic Cusp) plasma/field configuration. 
The bulk plasma would be itself sustained by an external refueling source in the assumed steady-state operating mode. Since the bulk plasma volume can be made large compared to the sheath plasma volume, the overall confinement time of the device can be enhanced over that predicted for simple mirror confinement by the bulk-to-sheath plasma volume ratio (10-100); this volume ratio represents the number of sheath particle inventories which the bulk plasma can replace.

As shown in Sec. III.C.2.a, the Tormac confinement scaling is Independent of toroidal aspect ratio. The reactor embodiment, however, wily be constrained by a minimum major radius to allow for the relatively fixed thicknesses of blanket/shield/coil structure on the inboard side of the plasma. An upper bound on the aspect ratio will be imposed by considerations of maximum desirable power output from a reactor with fixed first-wall power density, plasma density and minor radius. Despite thesé restrictions, the Tormac reactor, relative to a tokamak, should exhibit flexibility in sizing and access for injection and maintenance.

A thorough review and assessment of the ongoing Tormac theoretical and experimental effort is beyond the scope of this report. The promise of high-beta, steady-state operation in a device with relaxed technological problems has stimulated a need to survey the parameter space available for Tormac reactor extrapolations. In this process crucial physics uncertainties requiring further theoretical and experimental research can be identified. At the preliminary level of this study a reference Tormac reactor design is not proposed or elaborated in any detall. Instead, sample design points taken from parametric design curves (Sec. III D.1) are identiffed and used to illustrate potential Tormac operating characteristics (Sec. III.D.4).

In essence, therefore, this scoping study establishes the reactor potential of the Tormac on the basis of a simplified but self-consistent physics mode1. Considerable theoretical analysis and invention is required to verify or to disprove the physics assumptions upon which this preliminary reactor assessment is based. Such an extension of Tormac theoretical physics would also benefit the Tormac experimental program, which at its present level is capable of contributing very little to this reactor analysis. Specifically, the physics of field/particle transport in the sheath region, the conditions for existence of a thin (few ion gyroradi1) sheath, transport within the sheath to the cusp extremities, bulk plasma transport, and the 
magnetic field configuration needed to achieve a minimum-B configuration in a high-beta plasma are poorly understood on both theoretical and experimental grounds. These uncertainties would require a major theoretical effort to resolve and have seriously limited the scope of this reactor study.

The Tormac reactor concept that has evolved from this preliminary study is summarized in the Executive Summary (Sec. II). Crucial aspects of the Tormac physics model and reactor energy balance are described and parametrically evaluated in Sec. III. Section IV presents a summary evaluation of the Tormac reactor concept that has evolved from this study. The limitations of both this study and the present Tormac physics basis do not permit a quantitative analysis of crucial uncertainties: startup, plasma sustenance and control (heating and fueling), bulk-plasma and sheath transport, sheath/mirror physics and high-beta minimum-B equilibrium. Central to these issues is the existence and form of the claimed minimum-B equilibrium configuration; these crucial magnetics considerations have been modeled as part of this study and are described in the Appendix. Uniortunately, this latter problem proved to be sufficiently difficult to preclude adoption of the equilibrium/magnetics results into a significant advancement of the Tormac reactor emboriment within tie time-scale of this study.

\section{EXECUTIVE SUMMARY}

The particular version of the Tormac magnetic confinement scheme considered here is the toroidal two-pole configuration (bicusp) ${ }^{4-5}$ as illustrated schematically in Fig. 1. Figure 2 depicts the Tormac physical arrangement in more schematic detail. The high-beta bulk (closed field lines) plasma on the toroidal magnetic field, $B_{\phi}$, is surrounded by the sheath (open field lines) plasma containing both toroidal and poloidal, $B_{\Theta}$, components. The field produced by the toroidal field coils (TFC) dominates on the inside of the torus and the field produced by the poloidal field coils (PFC) dominates on the outside of the torus. The combined $B_{\phi}$ and $B_{\ominus}$ fields can be shown to produce a minimum-B magnetic well that is essential for plasma stability and equilibrium (see Appendix). The plastna cross-sectional shape indicated on Fig. 2 is characteristic of this bicusp confinement geometry. Field mapping computations of self-consistent designs of coil locations and currents leading to the minimum-B magnetic well are discussed in the Appendix. It suffices for purposes of this study to assume favorable confinement and to 


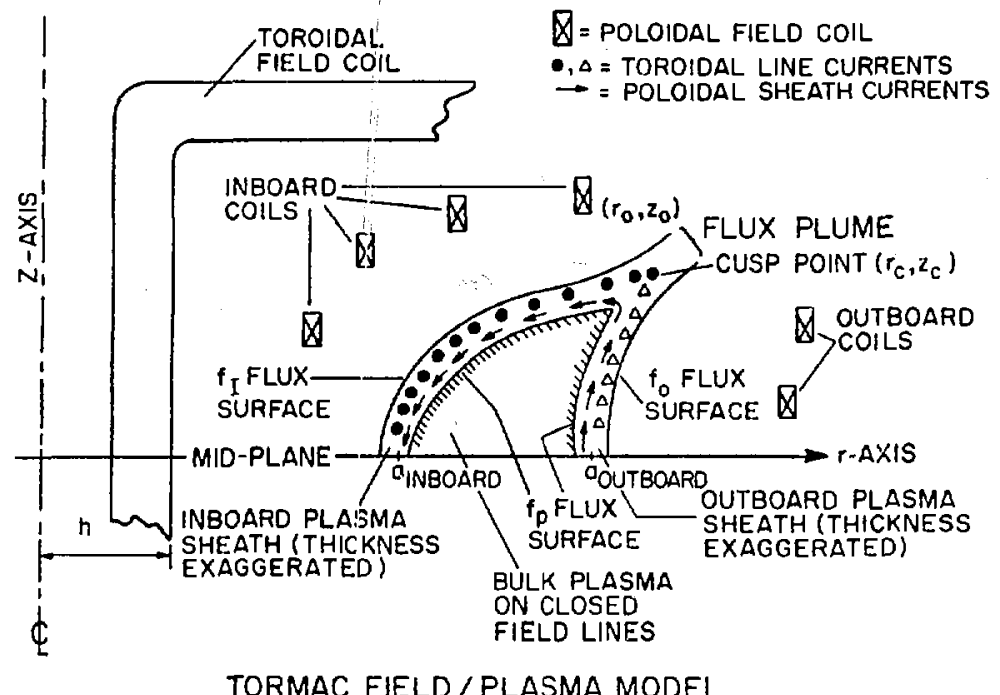

TORMAC FIELD / PLASMA MODEL

F1g.2. Schematic layout of the Tormac plasma/magnet arrangement. The power ganerating blanket would be placed between the toroida1-bicusp plasma and the magnet coils (toroidal field coils (TFC) and poloidal field coils (PFC)).

vary parametrically several crucial plasma parameters in order to estimate the resultant reactor performance. Through this process, critical tradeoffs (e.g., between power level, reactor size, and recirculating power fraction) can be Identified. Using this approach the major proponents of the Tormac concept have published several papers directed at the extrapolation of the Tormac device to the $\mathrm{D}-\mathrm{T}$ commercial reactor regime. ${ }^{6-9}$ The most comprehensive of these papers ${ }^{8-9}$ are based on scaling and parametric studies of the Tormac using classical mirror confinement of the sheath plasma.10-11 Using a similar model, the LASL group has also explored Tormac reactor scaling.12-14 This report is an amplification and extension of those interim LASL results and may be considered to supersede them. The simple reactor model and energy balance used for this report differ little from that used in Refs. 8-9. Emphasis is placed upon the sensitivity of the Tormac reactor performance to the cusp confinement time, electron-to-ion temperature ratio and plasma beta. The algorithm used here is more general and the parameter variations are more extensive than those presented in Refs. '8-9. An attempt is also made to Include all major energy terms in the steady-state Tormac plasma energy 
balance, although some of these terms may be negligible in certain parameter ranges. More importantly, however, explicit and self-consistent expressions are given for all aspects of the plasma energy balance, in order that differences in results can be more readily identifled. Whenever possible less sensitive parameters are chosen to agree with those assumed in Refs. 8-9.

The baslc assumptions of the model used for this study are summarized in Table I. The design basis of the Tormac reactor may be considered as optimistic in the sense that many detailed calculations and experiments have not been performed; such calculations are needed to justify the assumption of stable steady-state operation, mirror-like confinement times that are enhanced by the bulk-to-sheath plasma volume ratio, and favorable coupling of the heating mechanism to the plasma. The primary intent here is to present a range of parameters where viable reactor operating points may be found. A viable operating point at this level of study is one which appears promising from the simultaneous viewpoints of low recirculating power, low to modest net electrical power output, modest physical size and acceptable first-wall

\section{TABLE I}

\section{BASIC ASSUMPTIONS AND DESIGN BASIS FOR TORMAC REACTOR STUDY}

- Steady-state operation and energy balance

- Re-fueling and/or energy injection method not specified

- Sheath particles mirror confined at unspecified distance beyond cusps

- Flat pressure profile in bulk plasma and sheath thickness equal to few ion gyroradii (i.e. point model of a homogeneous plasma)

- Plasma beta, $\mathrm{T}_{e} / \mathrm{T}_{i}$, sheath width, alpha-particle trapping and size parametrically specified

- Magnet and field conflguration not specifled, but assumed to provide favorable curvature and stable equilibrium everywhere

- Major plasma losses are cusp leakage, untrapped alpha particles, bremsstrahlung, and cyclotron radiation

- Plasma start-up, maintenance, and sustenance issues are ignored

- MHD-stable sheath with plasma pressure supported by steep pressure gradients within the sheath (current- and gradient-driven instabilities are shear stabilized)

- Impurity effects neglected (sheath shields bulk plasma from wall impurities)

- Simple toroidal geometry spectffed by an effective minor wall radius $\mathbf{r}_{w}$, major radius $R$, and plasma minor radius $r_{p}=x r_{w}$

- Focus on energy-balance trade-off with reactor size $\left(r_{w} \times R, P_{E}\right)$ and $14.1-M \in V$ neutron wall loading $I_{w}$ 
loadings. Potential operating points meeting most of these criteria have been identified but, since their performance is critically sensitive to the as yet unresolved sheath physics and plasma/field configuration, elaboration of a detailed Tormac reactor reference design was deemed premature and inadvisable at this time. Effort to elucidate crucial uncertainties in Tormac physics and thereby narrow the reactor parameter space, however, does seem worthwhile.

In this spirit, a specific Tormac operating point is not proposed or defended in this study. Rather, the uncertainty in and sensitivity of Tormac reactor operation to these physics issues suggests the following areas of near-term investigation:

- a more realistic and quantitative model for Tormac sheath physics and transport

- a time dependent, radlal-profile-averaged thermonuclear burn simulation which addresses startup, thermal stability, the coupling of the heating mechanism and steady-state operation

- a comprehensive high-beta plasma/magnetics computation performed self-consistently with the above two items

- a more relistic and comprehensive energy balance than that used here.

The several comprehensive parametric design curves presented in Sec. III.D.l provide a means of examining the general scaling relationships, trade-offs, and constraints of Tormac recctor operation at a preliminary but useful level. For the purposes of this Executive Summary, one of the more optimistic reactor design curves is depicted on Fig. 3 for the fixed parameters shown: first-wall $14.1-\mathrm{MeV}$ neutron wall current $I_{W}\left(\mathrm{MW} / \mathrm{m}^{2}\right)$, plasma aspect ratio $\mathrm{R} / \mathrm{r}_{\mathrm{p}}$, alpha-particle trapping efficiency $\mathrm{f}_{\alpha}$, neutral beam (or rf-heating) injection efficiency $n_{I N J}$, thermal-to-electrical conversion efficiency $\eta_{\mathrm{TH}}$, plasma beta $\beta$, electron-to-ion temperature ratio $\lambda$, and number of ion gyroradii across the plasma sheath $f_{s^{*}}$ Figure 3 depicts the relationship between net electrical power $P_{E}$ (MWe) and engineering $Q$-value $Q_{E}$ (inverse of recirculating power fraction, $\varepsilon=1 / Q_{E}$ ) for a fixed plasma radius $r_{p}$. The point-plasma reactor scaling (Sec. III.C.2) permits lines of constant ion temperature $T$ and product of average plasma radius and magnetic field, $r_{p} B$, to be displayed. In essence, therefore, Fig. 3 and figures similar to it (Sec. III.D.1) represent the range of possible Tormac reactor designs predicted within the constraints of the zeroth-order plasma model. This particular set of Tormac design curves is optimistic, particularly with respect to the assumed $\beta=0.7, f_{S}=2, n_{I N J}=0.7$, and the assumption of unspecified startup and stable steady-state plasma sustenance. None of the 


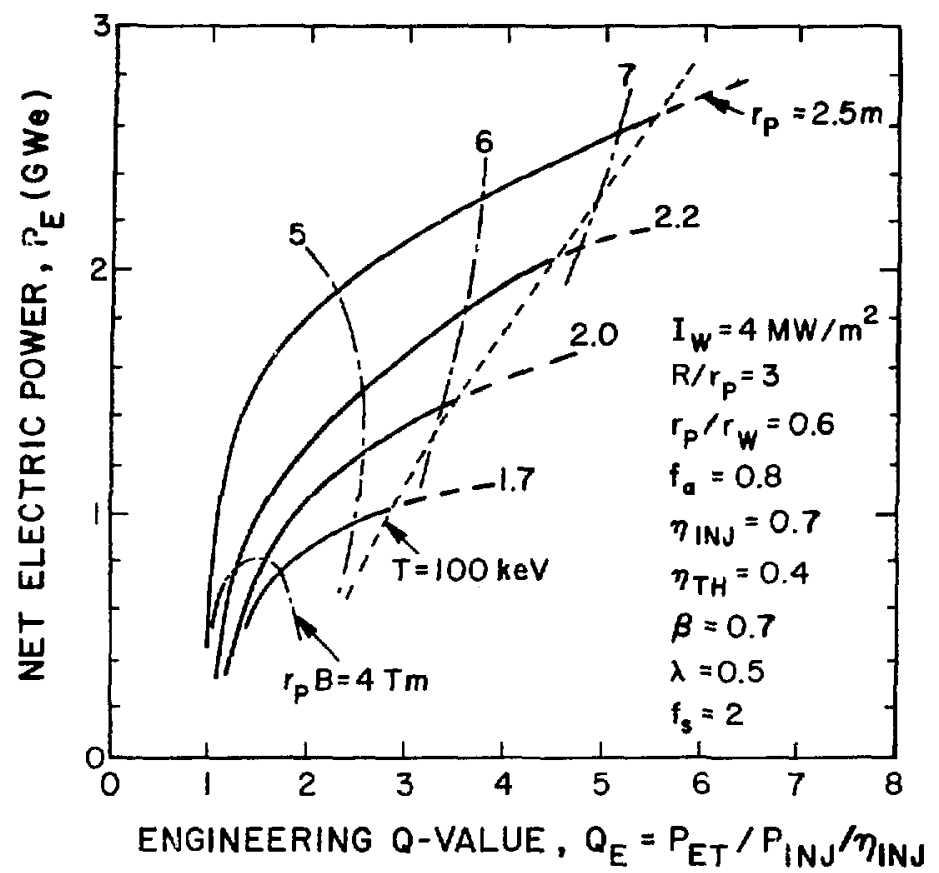

Fig.3. Parametric dependence of net electrical power, $P_{E}(M W e)$, on the engineering $Q$-value, $Q_{E}$, for the fixed parameters indicated (refer to text for notation).

potential Tormac operating points depicted in Fig. 3 is ignited (i.e., zero injection power, $P_{I N J}$, and $1 / Q_{E} \rightarrow 0$ ), and computations were not carried beyond plasma temparatures of $100 \mathrm{keV}$.

The important features of the Tormac reactor are operation at high plasma temperatures (characteristic of mirror-confinement scaling), modest magnetic fields at the plasma, a need to operate in a driven mode $\left(1 / Q_{E}>0\right)$ for acceptably low power levels. The overall Tormac reactor performance appears highly sensitive to the sheath thickness, $f_{S}$, expressed in units of ion gyroradif. Aside from the unresolved (and unstudied) issues of sheath and bulk plasma stability in a presumed achievable steady state, these interrelated issues of sheath thickness, confinement scaling, and resultant reactor performance must be resolved before more profound Tormac reactor studies are performed. A necessary first step in projecting the Tormac reactor embodiment beyond the idealized and parametric level adopted by this study is the self-consistent resolution of the bicusp plasma shape. A 
resolution of the high-beta minimum-B Tormac configuration was attempted by this study (Appendix) in order that other design features (heating access, blanket/shield configuration, coll(s) design) of the Tormac reactor could be brought into a sharper focus. The calculation of the minimum-B bicusp equilibrium proved difficult and could not be incorporated into the reactor design within the allotted study period. The results of this state-of-the-art equilfbrium calculation, nevertheless, are described in the Appendix and have been used in the following section to check the feasibility of constructing a Tormac configuration consistant with the results of the power-balance model for a typical operating point.

III. THE TORMAC REACTOR CONCEPT

A. Description of Reactor Core

A detailed, self-consistent engineering design of a Tormac reactor has not been performed to date. However, insofar as the Tormac could share many engineering features with other more developed magnetic-fusicn concepts (e.g., neutral-beam heating, superconducting coils, pellet refueling, divertors and power supplfes), it is assumed here that the appropriate technological research and development program is available and could be called upon to generate design details if required. At this level of study it suffices to Identify those inherent or unique features of the Tormac which either relax the required technology (e.g., lower fields or lower voltage) or make special technological demands.

Using results from the magnetics computations given in the Appendix, a schematic of a representative Tormac plasma/coil configuration is illustrated in Fig. 4. A more detailed discussion of this reactor configuration appears in the Appendix and in Sec. III.D.4. The toroidal field coil (TFC) set indicated in Fig. 2 is compatible with this configuration. Not shown in Fig. 4 are any details of blanket structure or penetration. The anticipated openness of the coll conflguration, however, should allow for flexible engineering design options for these features. Because the Tormac confinement scaling is independent of toroidal aspect ratio, a relatively accessible torus can be postulated. 


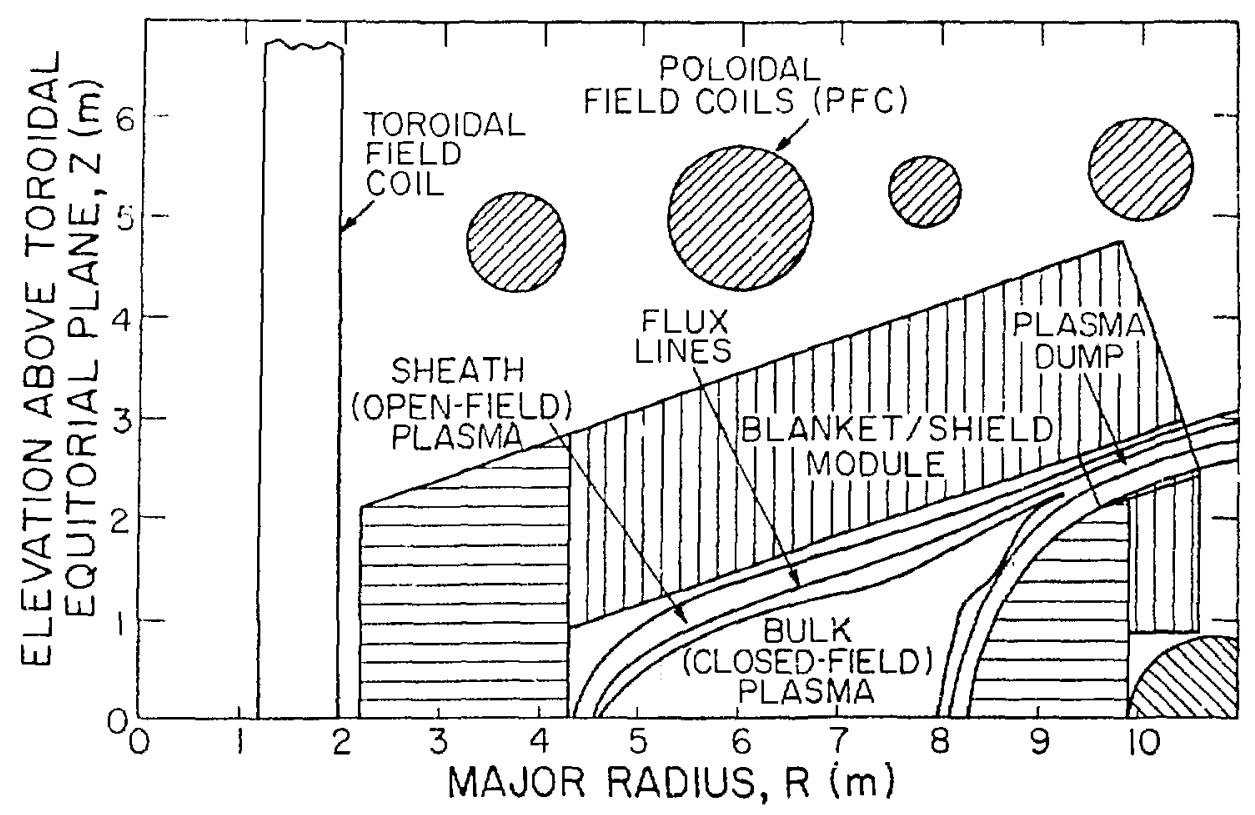

Fig. 4. Schematic scale representation of the Tormac plasma/blanket/coil configuraticn that would be consistent with the required fleld configuration (refer to Appendix).

\section{B. Description of Reactor Operation}

Tormac experimental plasmas are initiated by implosion techniques similar to those used to form a classical theta-pinch discharge. The high voltages that this would entail in the reactor embodiment suggest an alternative start-up approach that might be similar to a tokamak discharge initiated near the inside of the toroidal chamber where the steady-state toraidal magnetic field is dominant. If this plasma is then allowed to expand radially outward along the major radius until an equilibrium with the pololdal field is reached and a suitable sheath is estabilshed, the plasma may provide a target plasma for subsequent density buildup and heating by neutral beams. In addition to unresolved energy losses associated with this "puffer" scheme for Tormac plasma buildup, the attalnment of the bicusp configuration by means other than high-voltage shock heating is not proven. If a steady-state operation should provs feasible, however, like the tokamak, a considerable energy loss could be tolerated during the startup phase. The transfent energy loss associated with the transformation from a q-stabilized expanding tokamak configuration to the minimum-B Tormac, however, can only be subjected to conjecture. 
In a driven mode, neutral-beam injection or auxiliary magnetoacoustic heating appear compatible with the Tormac concept. Design points in an ignited mode also seem accessible although the total power output maybe unattractively large. With pellet refueling and an adequate rate of alpha-particle ash removal under the conditions of low impurity penetration to the bulk plasma, quasi-steady operation seems possible. Detailed calculations of these processes or other limitations on burn pulse length (e.g., field diffusion) have not been performed. The assumption of steady-state operation used In the power balance calculations of the next section must be viewed as a convenient and optimistic assumption pending the availability of a better Tormac physics data base. Further advantages claimed for the Tormac reactor concept include relatively high-beta operation, which cends to reduce the required field strength for a fixed power output and also reduces the cyclotron radiation loss rate at the high-temperature operation required to take advantage of the mirror-like scaling, (i.e., long ion-ion collision times in the sheath region).

\section{Tormac Reactor Power-Balance Model}

\section{Overall Model and Design Basts}

Figure 5 depicts a stylized diagran of the Tormac reactor power balance mode1. Although the steady-state, Maxwellian D-T plasma is described by one component (1ons), the effect of differences in electron and ion temperatures on pressure balance and radiation losses is included by the parameter $\lambda=\mathrm{T}_{e} / \mathrm{T}_{i}$. The plasma is assumed to have no internal. structure, but instead is described by an effective minor radius $r_{p}(m)$ and major radius $R(m)$. Ion and electron cusp losses $P_{\ell}(W t)$ and the fraction $1-f_{\alpha}$ of the total alpha-particle power $\mathrm{P}_{\alpha}(W t)$ lost from the plasma (primarily through the cusps) are recovered by the thermal cycle, as are the neutron power $\mathrm{P}_{\mathrm{N}}(\mathrm{Wt})$, the bremsstrahlung radiation $\mathrm{P}_{B R}(W t)$ and the cyclotron radiation $\mathrm{P}_{C Y}(W t)$. The total thermal power

$$
P_{T H}(W t)=P_{\ell}+\left(1-f_{\alpha}\right) P_{\alpha}+P_{N}+P_{B R}+P_{C Y}
$$

Is assumed to be converted with efficiency $n_{\mathrm{TH}}$ to electrical power $P_{E T}($ We $)=\eta_{T H} P_{T H}$. Only the total electrical power $P_{\text {INJ }} / n_{\text {INJ }}$ needed to drive an unspecifled energy/particle injector (e.g. neutral beams) at an efficiency 


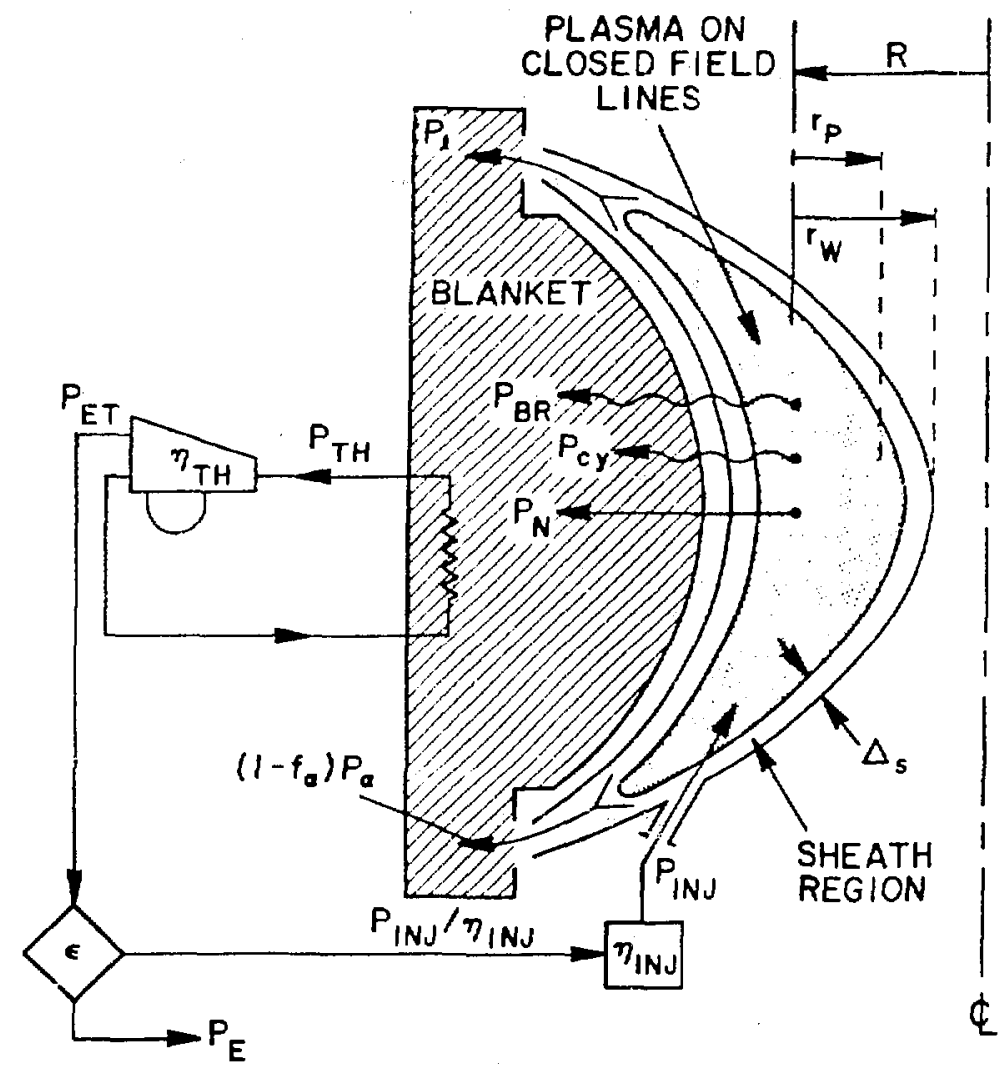

Fig. 5. Schematic diagram of the idealized Tormac reactor power balance.

"INJ is assumed to contribute to the recirculating power; the power $P_{\text {INJ }}$ (Wt) is simply that needed to maintain the Tormac plasma in a thermal steady state. That is,

$$
\mathrm{P}_{I N J}(W t)=\mathrm{P}_{\ell}+\mathrm{P}_{\mathrm{BR}}+\mathrm{P}_{\mathrm{CY}}-\mathrm{F}_{\alpha} \mathrm{P}_{\alpha}
$$

which is identical to the plasma energy balance used in Ref. 9 if the alpha particle loss is assumed to be recovered in the thermal cycle. Hence, the fraction of the total electrical power generated by the Tormac reactor that must be recirculated to assure a thermal steady state is given by 


$$
E=\left(\mathrm{P}_{\mathrm{INJ}} / \mathrm{n}_{\mathrm{INJ}}\right) / \mathrm{P}_{\mathrm{ET}}
$$

All results are expressed either in terms of an engineering $Q-v a l u e, Q_{E}=1 / \varepsilon$, or the net electrical power $P_{E}=P_{E T}(1-\varepsilon)$. Both $Q_{E}$ and $P_{E}$ (We) have been parametrically evaluated as a function of ion temperature $T(k e V)$, with the first-wall 14.1-MeV neutron current, $\mathrm{I}_{\mathrm{W}}\left(\mathrm{MW} / \mathrm{m}^{2}\right)$, serving as a major constraint. The effective first-wall radius is denoted by $r_{W}(m)$. No attempt is made $z o$ distinguish between the inner and outer neutron wall current, which for a small aspect-ratio torus and an elongated bicusp geometry could differ appreciably from the averaged value used. 9 Determination of these geometric effects for an equilibrium Tormac plasma is a complex task which was only touched upon by this study (Appendix).

The determination of the effective energy worth of each $14.1-\mathrm{MeV}$ neutron to the reactor thermal cycle depends upon neutronic calculations for specific blanket compositions and configurations. Representative results for several reactor designs are available in Refs. 15-29. These designs incorporate a variety of material compositions, structural material fractions and thicknesses, have various design goals and constraints and represent different calculational models. For purposes of this study, the simple estimate of $18.9 \mathrm{MeV} / \mathrm{n}$ (multiplication $\mathrm{M}=1.34$ ), 28 which is consistent with Ref. 9 , falls near the average $(\sim 1.31)$ of the range $(14.8-26.3)$ of values from Refs. 15-29. The direct-cycle blanket, 18,27 which has the potential reactor advantage of eliminating the secondary coolant loop generally assumed to be required as a tritium barrier, would have multiplication values somewhat lower than $M=1.34$. The Ref. 27 blanket/shield design $(\Delta r \sim 2 \mathrm{~m})$ was used to size the Tormac reactor schematic drawing in Fig. 4. The neutron power, $\mathrm{P}_{\mathrm{N}}$, is related to the $14.1-\mathrm{MeV}$ neutron wall loading by

$$
\mathrm{I}_{\mathrm{W}}\left(\mathrm{MW} / \mathrm{m}^{2}\right)=\left(\mathrm{P}_{\mathrm{N}} / \mathrm{M}\right) /(2 \pi)^{2} \mathrm{R} r_{\mathrm{W}}=\left(\mathrm{P}_{\mathrm{N}} / \mathrm{M}\right) /(2 \pi)^{2} \mathrm{xAr} \mathrm{r}_{\mathrm{W}}^{2}
$$

where $x=r_{p} / r_{w}$ and the plasma aspect ratio $A=R / r_{p}$. Generally, the major radius $R$ is taken as the centroid of the bicusp plasma cross section relative to the torus center, and the minor radius $r_{p}$ is defined such that $\pi r_{p}^{2}$ equals the cross-sectional area of the bicusped plasma. For the bicusp geometries 
considered the ratio of peak-to-average wall loading is expected to fall in the range $2-4$.

\section{Formulation of Tormac Reactor Power Balance}

a. Cusp Confinement Time.

Following the discussions in Refs. 9,11 and 30, a stable, thin sheath of thickness $\Delta_{s}$ is assumed to exist between plasma confined on closed magnetic field lines and reglons of open fleld lines. The sheath thickness is taken to be $f_{s}$ times the ion gyroradius, $r_{1}$, evaluated for the plasma conditions existing at the edge of the closed field reglon, where $r_{i}$ is given by

$$
r_{1}(m)=m_{1}^{1 / 2}\left(3(10)^{3} e\right)^{1 / 2} / Z e B=8.85(10)^{-3} T^{1 / 2} / 2 B
$$

where $e=1.602(10)^{-19} \mathrm{~J} / \mathrm{eV}$, and, except for the ion temperature $T(k e V)$, mks units are used. The average tons mass was taken as $2.5 \mathrm{amu}$ for a $50 / 50 \mathrm{D}-\mathrm{T}$ plasma, and $B(T)$ is the magnitude of the confining magnetic field at the plasma edge.

Ions within the sheath region are assumed to be mirror confined and, therefore, reside in the sheath region for approximately one ion-ion collision time $31,32, \tau_{\text {OII }}$, required for cumulative large angle scattaring.

$$
\begin{aligned}
\tau_{\theta i i}(s) & =25.8^{1 / 2} \varepsilon_{o}^{2} m_{i}^{1 / 2}\left(10^{3}\right)^{3 / 2} T^{3 / 2} /\left(z^{4} e^{4} n \ln \Lambda\right) \\
& =7.15(10)^{17} \mathrm{~T}^{3 / 2} /\left(z^{4} \mathrm{n} \ln \Lambda\right)
\end{aligned}
$$

The average particle loss time $\tau_{\ell}(s)$ is taken equal to $\tau_{\theta i i}$ multiplied by the number of sheath particle inventories that a plasma of nominal radius $r_{p}$ can supply. Hence,

$$
\begin{aligned}
\tau_{\ell}(s) & =\tau_{\Theta 11}\left(r_{p} / \Delta_{s}\right)=\left(\tau_{\Theta I 1} / r_{1}\right)\left(r_{p} / f_{s}\right) \\
& =8.07(10)^{19}\left(r_{p} B T\right) /\left(n z^{j} f_{s} \ln \Lambda\right) .
\end{aligned}
$$


Arguments can be made ${ }^{9}$ that the use of $\tau_{\text {OII }}$ for the ion residence $t$ ime in the sheath region is not strictly correct because of (cusp) geometry and mirror corrections. A number of processes occur in a mirrored configuration that will alter the simple picture that has led to the use of $\tau_{\circlearrowleft i 1}$ as the mirror confinement time. If large ambipolar potentials are established, the electrostatic drift of ions can significantly reduce the effective mirror ratio by $\sim 1 /(1+\lambda)$. Most importantly, however, are particle scattering events that occur near the mirroring points where the ion parallel velocity is small and the scattering frequency is high. Calculation of such geometry-dependent effects is difficult and has not been made for the expected cusp configuration. The ratio of mirror confinement time to $\tau_{\Theta i}$ for a parabolic mirror configuration, can be shown ${ }^{31}$ to equal 0.45 $\left.\left(\langle 1 / v\rangle_{\mathrm{TH}}<1 / \mathrm{v}^{2}\right\rangle_{\mathrm{TH}}\right) /\left(\langle 1 / \mathrm{v}\rangle\left\langle 1 / \mathrm{v}^{2}\right\rangle\right) \ln _{\mathrm{M}}$, where $\mathrm{R}_{\mathrm{M}}$ is the effective mirror ratio, \& indicates velocity spectrum averages, the subscript "TH" designates averages over a Maxwell-Boltzmann distributicn. For Maxwellian ions in the sheath region and $R_{M}=2$, the geometry correction referred to in Ref. 9 should amount to $\sim 0.63$. As noted in Ref. 31 , however, the use of this correction to $\tau_{O 11}$ is not applicable to mirrors with long central sections, and the cusp-like geometry probably is more closely associated with the latter than with a short, parabolic mirror configuration. The application to the cusp configuration of Fokker-Planck computations made for simple mirrors is also potentially incorrect, and more theoretical work seems in order. The source term in the mirror computations would properly be a narrow distribution in angle and energy characteristic of neutral-beam injection, while the source term for the Tormac sheath case would be the nearly isotropic and unknown energy distribution of the bulk-plasma leakage.

In arriving at Eq. (7) it has been assumed that the plasma pressure on open field lines equals the plasma pressure in the closed field region. If a fraction of the plasma pressure is supported on open fleld lines, the particle loss rate can be reduced compared to the predictions of Eq. (7). Furthermore, if the sheath electrons can be maintained considerably hotter than in the bulk plasma ${ }^{33}$ the corresponding density reduction in the sheath region would Increase $\tau_{\ell}$ by $\sim \beta^{1 / 2}\left(n / n_{s}\right)^{2}$, where $n_{s}$ is the average sheath density. Generally, increases in $\tau_{\ell}$ of $\sim 60$ are expected if these processes prove possible. 33 
In addition to these reasons for achieving a hot electron sheath (1.e., low sheath density), the stability of the sheath points towards the desirability of hot electrons in this region. Furthermore, if the sheath electrons become too cold, Ion-electron equipartition will drag sheath ions Into the loss cone, and $\tau_{\ell}$ will be reduced by $\left(1+\tau_{\theta 11} / \tau_{1 e}\right)$, where $\tau_{i e}$ is the Ion-electron equilibration time. ${ }^{34}$ Lastly, the presence and effects of micro-turbulence in the sheath region, leading to a smoothing of idealized (peaked) pressure profiles and generally enchancing transport, is unresolved at this time.

Since both experimental and theoretical understanding of the sheath physics, beyond the simple basis of Eq. (7), is obscure at this time, Eq. (7) is used for all analyses presented here, after it has been brought in line with the scaling relationship used in Ref. 9 i.e.,

$$
\tau_{\ell}(s)=4.5(10)^{17} \mathrm{r}_{\mathrm{p}} \mathrm{BT} / \mathrm{n} .
$$

Since $f_{s}$ was assumed to equal 2 in Ref. 9, agreement between Eqs. (7) and (8) for $2=1$ and $\ell n \Lambda=17$ is obtained by 1ntroducing a "geometry/mirror" correction factor $g=0.19$. This correction is consistent with Boozer, 35 who states that the best estimate of Tormac confinement is $\sim 10 \%$ of $\tau_{011}\left(r_{p} / r_{1}\right)$. For the sake of this analysis, therefore, a geometric/mirror factor $g$ is introduced, $\ell n \Lambda$ is fixed at 17 and $Z$ is taken as unity to give the following expression for $\tau_{\ell}$

$$
\tau_{\ell}(s)=\left(g / f_{s}\right)\left(n / n_{s}\right)^{2} 4.75(10)^{18} 8_{B} 1 / 2 r_{p} B T / n\left(1+\tau_{\theta i i} / \tau_{1 e}\right) .
$$

When $f_{s}=2,\left(n / n_{s}\right)=1, \tau_{\Theta 11} / \tau_{1 e}=0$ and $g=0.19$ complete agreement occurs with $\tau_{\ell}$ given in Ref. 9. No attempt to compute either $n / n_{s}$ or $g$ is made here, and $\tau_{\theta i i} / \tau_{1 e}$ is set equal to zero for all parameter studies.

The understanding of the Tormac sheath structure appears sufficiently qualitative to render $\tau_{\Theta_{11}} / \tau_{1 e}, g$ and $n / n_{s}$ little more than guesses at this time. It is easily shown, ${ }^{36}$ however, that the existence of a sheath dictates that $\Delta_{s}$ is at most a few lon gyroradil (i.e. $\left.f_{s} \leqslant 2\right)$. The performance of a Tormac reactor depends cruclally on both the scaling of $\tau_{\ell}$ with key plasma 
parameters as well as on the magnitude of $\pi / n_{s}, \tau_{\Theta i 1} / \tau_{i e}, g$ and $f_{s}{ }^{*}$ An examination of correctness and Iimitations of the $r_{p} B T / n$ scaling, however is beyond the scope of this study. The diffuse nature as well as the microstability of these sheaths represent at this time crucial unknowns and uncertainty for the Tormac reactor studies. An attempt has been made recently ${ }^{37}$ to use a simple, one-dimensional fluid model to examine the sheath structure and to quantify a few of these uncertainties. Although this work remains to be published, future more detalled Tormac reactor studies should focus onto this sheath issue.

Equation (9) is used to compute the cusp power loss $P_{\ell}(W t)=(3 / 2)(1+\lambda) n(k T) V_{p} / \tau_{\ell}$, where $V_{p}=2 \pi^{2} r_{p}^{2} R$. With $T(k e V)$ the ion temperature, $n / n_{s}=1$, and $\tau_{\ominus i 1} / \tau_{1 e}=0$ this loss becomes

$$
P_{\ell} /\left(V_{p} n^{2}\right)=5.06(10)^{-35}(1+\lambda)\left(f_{s} / g\right) / \beta^{1 / 2} r_{p} B,
$$

where a simple pressure balance,

$$
B B^{2} / 2 \mu_{o}=(1+\lambda) n(k T)=(10)^{3} e(1+\lambda) n T,
$$

has been used to eliminate the explicit density dependence.

Not Included in the scaling of Tormac confinement time $(\mathrm{Eq} \cdot(9))$ is the fact that a fraction of lons entering the sheath from the bulk plasma, assumed here to be isotropic in distribution, will have velocity vectors already in the phase-space mirror loss cones and need not undergo scattering collisions to be lost from the sheath. For an effective mirror ratio $R_{M}$, measured along the sheath length, the corrected Lawson parameter $\left(n \tau_{\ell}\right)^{\prime}$ otherwise calculated using Eq. (9) becomes

$$
\left(n \tau_{\ell}\right)^{\prime}=\left(n \tau_{\ell}\right)\left(1-1 / R_{M}\right)^{1 / 2} .
$$


The parameter $\left(\mathrm{nt}_{\ell}\right)$, however, already incorporates a mirror confinement factor consistent with $R_{M}=\sqrt{10}=3.162$. Equation (12), therefore, can be generalized to

$$
\left(n \tau_{\ell}\right)^{\prime}=\left(n \tau_{\ell}\right) 2\left(1-1 / R_{M}\right)^{1 / 2} \log _{10} R_{M} .
$$

For the value of $R_{M}(=3.162)$ assumed in this study and Ref. 9, the correction to $\tau_{\ell}$ is modest and certainly smaller than other uncertainties in the derivation of $\mathrm{Eq}$. (9). For stialler mirror ratios, however, Tormac particle confinement becomes increasingly degraded. This additional physics issue deserves near-term attention in order to make reactor extrapclations more credible.

\section{b. Bremsstrahlung Radiation Loss.}

For purposes of this study the effective charge of the plasma, is assumed to be unity. In essence, rapid alpha-particle ash removal and no impurity buildup is optimistically assumed. The energy loss associated with electron-ion bremsstrahlung radiation $P_{B R}(W t)$ is given by ${ }^{38}$

$$
\mathrm{P}_{\mathrm{BR}} /\left(\mathrm{V}_{\left.\mathrm{P}^{\mathrm{n}^{2}}\right)}=5.35(10)^{-37}(\lambda \mathrm{T})^{1 / 2}\right.
$$

Not included as a loss in this study or that of Ref. 9 is the electron-electron bremsstrahlung loss rate, which becomes the dominant process at high plasma temperatures. The corrected bremsstrahlung rate $P_{B R}$ relative to $P_{B R}$ is subject to some dispute in the 1iterature, which may account for 1 ts omission in reactor calculations in the high-temperature regime. Two estimates of the loss enchancement are summarized in Table II and indicate a potential concern for high-temperature reactor operation (e.g. advanced fuels $\left.{ }^{33}\right)$. 
TABLE II

RATIO OF ELECTRON-ELECTRON TO ELECTRON-ION BREMSSTRAHLUNG LOSS

\begin{tabular}{|c|c|c|c|}
\hline $\mathrm{T}_{\left.\mathrm{e}^{(\mathrm{keV})}\right)}$ & $\begin{array}{l}\mathrm{T}(\mathrm{keV}) \\
(\lambda=0.5)\end{array}$ & $\begin{array}{l}{ }_{P_{B R}} / P_{B R} \\
\text { (Ref. } 39) \\
\end{array}$ & $\begin{array}{l}\mathrm{BR}^{\prime} / \mathrm{P}_{\mathrm{BR}} \\
\left.\mathrm{Ref} \cdot \mathrm{H}^{\prime}\right)\end{array}$ \\
\hline 25 & 50 & 1.06 & 1.25 \\
\hline 50 & 100 & 1.13 & 1.401 \\
\hline 80 & 160 & & 1.541 \\
\hline 100 & 200 & 1.34 & 1.632 \\
\hline 150 & 300 & 1.64 & 1.872 \\
\hline 200 & 400 & & 2.135 \\
\hline 250 & 500 & & 2.432 \\
\hline 300 & 600 & & 2.739 \\
\hline 400 & 800 & & 3.44 \\
\hline 500 & 1000 & & 4.20 \\
\hline
\end{tabular}

c. Cyclotron Radiation Loss.

Depending upon $\beta, \lambda$, and the ion temperature $T$, which are dictared by as yet unresolved details of the bulk cusp-loss mechanism and transport in the bulk plasma, cyclotron radiation may not be negligible. The following expression for $\mathrm{P}_{\mathrm{CY}}(\mathrm{Wt})$ was used ${ }^{31}$

$$
{ }^{P_{C Y}} /\left(V_{P} n^{2}\right)=5.0(10)^{-38}(1 / \beta-1)(\lambda T)^{2}(1+\lambda T / 204) f_{H^{K}}
$$

The absorbtivity of the structural walls upon which the cyclotron radiation Impinges was treated simply by specifying a hole fraction, $\mathrm{f}_{H}$, whereas the transmistivity of the plasma is given by 31

$$
\begin{aligned}
& \kappa=2.1(10)^{-3}(\lambda T)^{7 / 4 / 2^{1 / 2}} \\
& \ell=\left(e / c \varepsilon_{o}\right) 2 r_{p} n / B_{i},
\end{aligned}
$$

where $B_{1}=(1-B)^{1 / 2} B$ is the average Internal (closed) magnetic field. Using pressure balance $(\mathrm{Eq} \cdot(11))$

$$
\kappa=3.83(10)^{-6}(1 / \beta-1)^{1 / 4} \lambda^{7 / 4}(1+\lambda)^{1 / 2} T^{9 / 4} /\left(\beta^{1 / 2} r_{p} B\right)^{1 / 2} .
$$


Cyclotron radiation, like electron-electron bremsstrahlung, becomes particularly important at high temperatures. These losses, therefore, are expected to become important for advanced-fuels applications.

d. Fusion Neutron Power.

The $D-T$ neutron power $P_{N}(W t)$ is given by

$$
\mathrm{P}_{N} /\left(v_{p} n^{2}\right)=\langle\sigma v\rangle E_{N} / 4
$$

where $E_{N}(J)=14.1(10)^{6} \mathrm{eM}$ to include the blanket energy multiplication $M$ as discussed in Sec. III.C.1. Values for the Maxwell-averaged D-T fusion reactivity are obtained as a function of $T(k e V)$ by interpolation between the standard values ${ }^{4,42}$ of Table III. It may be noted that the usual analytic expression ( $\mathrm{p}$. 20 of Ref. 38) is a poor representation of the $\langle\sigma v\rangle$ table in the temperature regime of interest to Tormac. ${ }^{42}$ References 8, 9, and 30 do not

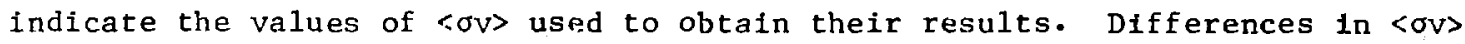
values at high plasma temperature may represent a possible source of discrepancies that may appear in a comparison of the results.

e. Alpha-Particle Power.

The total 3.5-MeV alpha-particle power, $P_{\alpha}(M W t)$, is given by $P_{N}(3.5 / 14.1 M)$. A fixed fraction $f_{\alpha}$ of $P_{\alpha}$ is assumed to be depostted into the plasma for eventual loss by radiation or through the ion/electron cusp-loss channels. The fraction $\left(1-f_{\alpha}\right)$ of $P_{\alpha}$ is assumed to be deposited directly into the thermal cycle primarily through the cusp-loss channel. The alpha-particle containment model used here is oversimplified and warrants more examination by future studies. A simllar statement can be made for any neutral-beam heating source assumed tó drive the Tormac reactor.

f. Engineering Q-Value and Net Power.

Equations (1-3) are combined to give the following expression for the engineering $Q$-value $Q_{E}=1 / \varepsilon$

$$
\mathrm{Q}_{\mathrm{E}} / \mathrm{\eta}_{\mathrm{TH}} \mathrm{\eta}_{\mathrm{INJ}}=\left(\mathrm{P}_{\ell}+\mathrm{P}_{\mathrm{BR}}+\mathrm{P}_{\mathrm{CY}}+\mathrm{P}_{\mathrm{N}}+\left(1-\mathrm{F}_{\alpha}\right) \mathrm{P}_{\alpha}\right) /\left(\mathrm{P}_{\ell}+\mathrm{P}_{\mathrm{BR}}+\mathrm{P}_{\mathrm{CY}}-\mathrm{f}_{\alpha} \mathrm{P}_{\alpha}\right)
$$

All powers that determine the dependence of $Q_{E}$ on $T$ depend only on the parameter $r_{\mathrm{p}} B$ for given values of $\beta$ and $\lambda$; if cyclotron radiation is negligible, the crucial varfable becomes $\beta^{1 / 2} r_{p} B$ for a given $\lambda$. A convenient 20 
TABLE III

D-T FUSION REACTIVITY TABLE

\begin{tabular}{|c|c|c|c|}
\hline $\begin{array}{l}\text { Maxwellian Ion } \\
\text { Temperature } \\
\mathrm{T} \text { (keV) } \\
\end{array}$ & $\begin{array}{l}\text { D-T } \\
\text { Reactivity } \\
\leq \text { ov }>\left(\mathrm{m}^{3} / \mathrm{s}\right) \\
\end{array}$ & $\begin{array}{l}\text { Maxwellian Ion } \\
\text { Temperature } \\
\mathrm{T} \text { (keV) }\end{array}$ & $\begin{array}{l}\mathrm{D}-\mathrm{T} \\
\text { Reactivity } \\
\text { Lov }>\left(\mathrm{m}^{3} / \mathrm{s}\right)\end{array}$ \\
\hline 0.05 & $7.00(-41)^{a}$ & 40.0 & $7.93(-22)$ \\
\hline 0.1 & $3.00(-36)$ & 50.0 & $8.54(-22)$ \\
\hline 0.5 & $6.00(-29)$ & 60.0 & $8.76(-22)$ \\
\hline 0.8 & $2.00(-27)$ & 70.0 & 8. $76(-22)$ \\
\hline 0.9 & $4.00(-27)$ & 80.0 & $8.64(-22)$ \\
\hline 1.0 & $6.27(-27)$ & 90.0 & $8.46(-22)$ \\
\hline 2.0 & $2.83(-25)$ & 100.0 & $8.24(-22)$ \\
\hline 3.0 & $1.81(-24)$ & 200.0 & $6.16(-22)$ \\
\hline 4.0 & $5.86(-24)$ & 300.0 & $4 \cdot 90(-22)$ \\
\hline 5.0 & $1.35(-23)$ & 400.0 & $4 \cdot 13(-22)$ \\
\hline 6.0 & $2 \cdot 53(-23)$ & 500.0 & $3.63(-22)$ \\
\hline 7.0 & $4 \cdot 14(-23)$ & 600.0 & $3 \cdot 28(-22)$ \\
\hline 8.0 & $6 \cdot 17(-23)$ & 700.0 & $3.02(-22)$ \\
\hline 9.0 & $8.57(-23)$ & 800.0 & $2.83(-22)$ \\
\hline 10.0 & $1 \cdot 13(-22)$ & 900.0 & $2.68(-22)$ \\
\hline 20.0 & $4 \cdot 31(-22)$ & 1000.0 & $2.55(-22)$ \\
\hline 30.0 & $6.65(-22)$ & & \\
\hline
\end{tabular}

a to be read as $7.00(10)^{-41}$

algrofthm based upon a mirror-like Tormac scaling, therefore, specifies an evaluation of $Q_{E}$ versus $T$ parametrically in the parameter $r_{p} B$ for chosen values of $B, \lambda, g / f_{s}, f_{\alpha}, n / n_{s}$, and $\tau_{\Theta i i} / \tau_{i e}$. As previously noted, for all computations presented here $n / n_{s}=1, \tau_{\theta i 1} / \tau_{i e}=0$ and $g=0.19$.

In addition to $Q_{E}$, the net electrical power output is of considerable interest. Hence, $P_{E}=P_{I N J}\left(Q_{E}-1\right) / n_{I N J}$ is evaluated as a function of temperature and parametrically in $r_{p} B$. It is easily shown that the convenient parameter here is $P_{E} r_{p} / A$, where the aspect ratio $A=R / r_{p}$. An algorithm that does not spectfy reactor size explicitly, therefore, evaluates $Q_{E}$ and $P_{E} r_{p} / A$ versus $\mathrm{T}$; the fusion-neutron wall loading $\mathrm{I}_{\mathrm{W}}$ is designated here as a major constraint. 
The simple definition of $Q_{E}$ embodied in Eq. (19) does not include an allowance for balance of plant (BOP) power requirements which can reasonably be estimated as $5 \%$ of the plant gross electrical output. A design estimated to operate at $Q_{E} \sim 5$ by $E q$. (19), therefore, will in fact operate with $Q_{E} \sim 4$ when $B O P$ requirements are included. Also not included are such power losses as Joule dissipation in normal coils or the refrigeration power requirement of superconducting colls. In short, a recircliating power estimate done more realistically can be expected to be higher by an additional 10-20\% than one obtained using the results of this study or those of Refs. 9 and 30.

\section{g. Wall Loading Constraints.}

The dependence of $Q_{E}$ and ${ }_{E} r_{p} / A$ on $T$ and the parameter ${ }_{p} B$ for given values of $B, \lambda, f_{s}$ and $x=r_{p} / r_{w}$ must be constrained by either the fusion neutron wall loading $\mathrm{I}_{\mathrm{W}}\left(\mathrm{MW} / \mathrm{m}^{2}\right)$ (i.e., first-wa11/blanket damage-rate versus life-time constraint) or the radiation thermal loading $I_{R A D}\left(\mathrm{MW} / \mathrm{m}^{2}\right)=$ $I_{B R}+I_{C Y}$ (i.e., a steady-state heat-flux constraint). It is easily shown that

$$
\begin{gathered}
\mathrm{I}_{W^{\mathrm{P}}} \mathrm{r}_{\mathrm{P}}^{3}(\mathrm{MWn})=1.72(10)^{24}\left(\langle\sigma \mathrm{V}\rangle / \mathrm{T}^{2}\right)\left(B^{1 / 2} \mathrm{r}_{\mathrm{p}} \mathrm{B}\right)^{4} \mathrm{x} /(1+\lambda)^{2}, \\
\mathrm{I}_{\mathrm{RAD}} \mathrm{r}_{\mathrm{p}}^{3}(\mathrm{MWn})=\left(1.64 / \mathrm{T}^{3 / 2}\right)\left(\beta^{1 / 2} \mathrm{r}_{\mathrm{p}} \mathrm{B}\right)^{4} \times \lambda^{1 / 2} /(1+\lambda)^{2}[1+\xi] . \\
{\left[\xi=0.09(\lambda \mathrm{T})^{3 / 2}(1+\lambda \mathrm{T} / 204)(1 / \beta-1) \mathrm{K}\right]}
\end{gathered}
$$

For all computations presented here, the dependence of $Q_{E}$ and $P_{E}{ }_{p} / A$ on $T$ and $r_{p} B$ are determined, and lines of constant $I_{W} r_{p}^{3}$ are shown to emphasize the wall loading constraint. The radiation loading on the first wall is relatively small for most cases of interest. The resulting design curves allow the trade-offs between $Q_{E}, P_{E}, I_{W}$ and reactor size ( $R$ and $r_{p}$ ) to be conveniently summarized and examined as a function of $T$ for fixed values of other variables (e.g., $x=r_{p} / r_{w}, n_{I N J}, n_{T H}$, etc). By means of such design curves the variation of or access to interesting operating points can be investigated as more crucial variables (e.g., $g, f_{s}, \beta, \lambda, n / n_{s}$, etc.) are changed. The selection of a specific design point based upon this limited model is not intented, but, 22 
rather the dependence and/or sensitivity of a range of possible operating points to crucial plasma and system parameters is examined.

\section{Evaluation of Reactor Mode1}

1. Parametric Study

Equation (19) is evaluated parametrically as a function of ion temperature $T$ and the parameter $r_{p} B$ for a reference case that is very similar to the conditions reported on Fig. 6 of Refs. 9 and $30\left(\mathrm{r}_{\mathrm{p}} / \mathrm{r}_{\mathrm{w}}=0.6, \mathrm{f}_{\alpha}\right.$ $\left.=0.8, n_{\text {INJ }}=0.7, n_{\text {TH }}=0.4, \beta=0.7, \lambda=0.5, f_{H}=0.1, f_{s}=2, \quad g=0.19\right)$. The net power, $P_{E}$, is similarly evaluated in the form $P_{E} r_{p} / A$ as a function of $T$ and $r_{p} B$. Figure 6 shows the dependence of $Q_{E}$ and $P_{E} r_{p} / A$ on $T$ and $r_{p} B$; lines of constant $\mathrm{I}_{\mathrm{W}} \mathrm{r}_{\mathrm{p}}^{3}$ [Eq. (20)] are also included. Computations were made only up to $T=100 \mathrm{keV}$, although in some instances viable operating points may be forced to temperatures that are above this arbitrary cut-off. Figure 6 represents all possible operating points for the set of fixed parameters indicated. Ignition ( $1 . e ., 1 / Q_{E}=0$ ) occurs only for a narrow range of temperatures at the maximum $r_{p}$ B values considered (Fig. 6).

Specification of the first-wall loading contalnment $I_{W}$, the plasma radius $r_{p}$, and the major radius $R$ permits an evaluation of $Q_{E}$ and $P_{E}$ for specific design points. The relationship between $P_{E}$ and $Q_{E}$ for a range of $r_{p}$ values is depicted on $\mathrm{Fig} \cdot 7$ for $A=R / \mathrm{r}_{\mathrm{p}}=3$ and $\mathrm{I}_{\mathrm{W}}=4 \mathrm{MW} / \mathrm{m}^{2}$, which are values selected for comparison with the cases considered on Fig. 6 of Refs. 9 and 30 . Shown also on Fig. 7 are lines of constant $r_{p} B$, from which the required fields can be determined. The 100-keV computational cut off is also designated, but should not be viewed as an intrinsic limft. Generally, $P_{E}$ must exceed 1500 MWe, $r_{p}>2 m$, and ion temperatures near $100 \mathrm{keV}$ are required if $Q_{E}>4 \quad(\varepsilon<0.25)$ for the fixed parameters given on Fig. 7 .

Figure 8 illustrates in the $P_{E}$ versus $Q_{E}$ format the effect of decreasing $B$ from 0.7 to 0.35 for the reference case (Fig. 7). The relationship between $P_{E}, Q_{E}$ and $r_{p}$ remains approximately the same as that given for the reference case (Fig. 7), but lines of constant $r_{p} B$ show a relative increase necessary to maintain an approximately equivalent net power output as $B$ is decreased. The effect of increasing the electron-to-ion temperature ratio $\lambda$ from 0.5 to 1.0 relative to the reference case (Fig. 7) is shown in Fig. 9. Increased $\lambda=\mathrm{T}_{\mathrm{e}} / \mathrm{T}_{1}$ enhances all loss terms $\left(\mathrm{P}_{\ell}, \mathrm{P}_{\mathrm{BR}}\right.$, and $\left.\mathrm{P}_{C Y}\right)$, dramatically increasing the value of $P_{E}$ required to achieve a given $Q_{E}$. Increased $\lambda$ appreciably limits the range of operating-point options (compare Fig. 9 to Ffg. 7 ). 

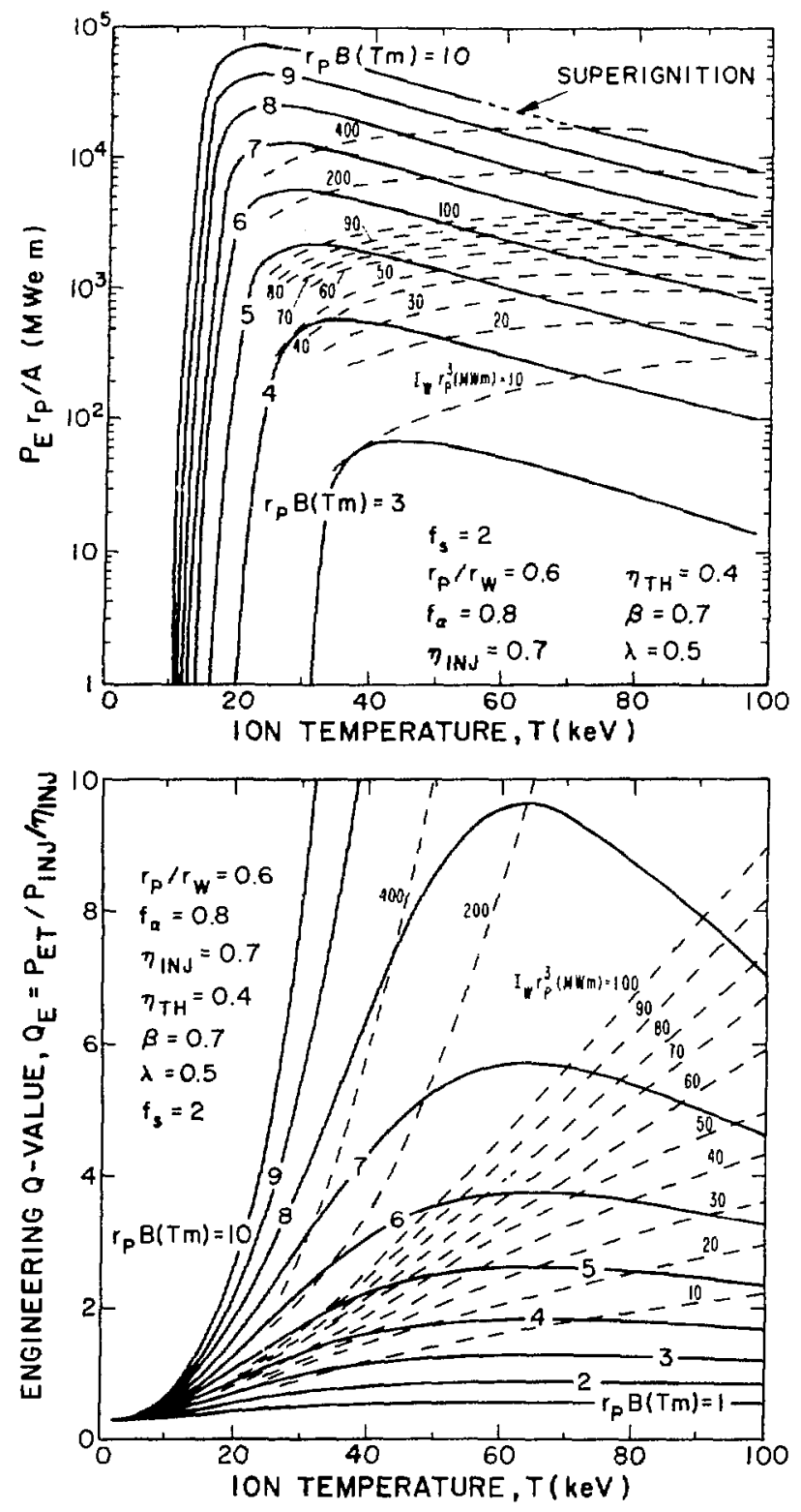

Fig. 6. Dependence of engineering Q-value, $Q_{E}$, and net power $P_{E}$ on ion temperature $T(\mathrm{keV})$ and $r_{p} B$ for the fixed parameters shown. Lines of constant $\mathrm{I}_{\mathrm{W}} \mathrm{r}_{\mathrm{p}}^{3}(\mathrm{MWm})$ are also shown $\mathrm{p}_{\text {reference case). }}$

As noted previously, the performance of the Tormac reactor is sensitive to the magnitude of the sheath parameters $\left(g, f_{s}, \pi / n_{s}, \tau_{\theta_{11}} / \tau_{1 e}\right)$ if the constraints of fusion neutron wall loading $I_{W}$ and the net electric power $P_{E}$ are imposed. As shown in Fig. 10, decreasing $f_{s}$ from 2 to 1 makes all 


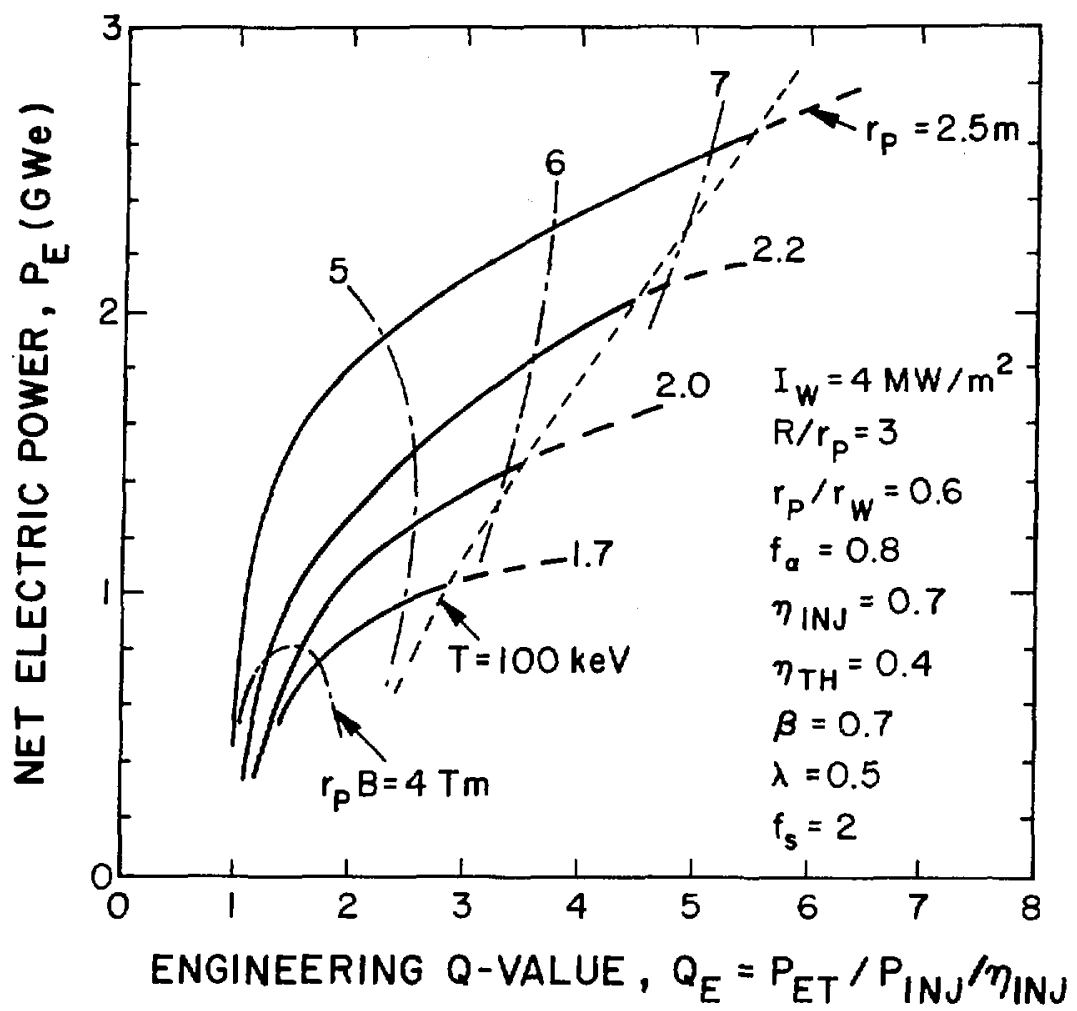

Fig. 7. Evaluation of reference case $(F i g \cdot 6)$ for $I_{W}=4 \mathrm{MW} / \mathrm{m}^{2}$ and $\mathrm{R} / \mathrm{r}_{\mathrm{p}}=3$.

operating points with $\mathbf{r}_{p^{B}}$ above approximately 5 Tm and $T>30$ keV "superignited." "Superignited" simply means that the power input to the plasma exceeds the plasma losses, even if $P_{\text {INJ }}=0$. Given this desirable circumstance, a means would have to be found to spoil the Tormac confinement In order that a steady-state be maintained. Although for the sake of discusston $f_{s}$ has been decreased in $\mathrm{Fig} \cdot 10$, since $n / n_{s}=1$ and $\tau_{\Theta i i} / \tau_{i e}=0$ for all computations, it is actually the product $\left(1+\tau_{\Theta i 1} / \tau_{i e}\right) f_{s} /\left(n / n_{s}\right)^{2}$ which was changed. Hence, a parametric decrease in sheath thickness $\left(f_{s}=\Delta_{s} / r_{1}\right)$ is equivalent to a corresponding increase in $n / n_{s}$, etc. Figure 11 gives the $Q_{E}$ and $P_{E} r_{p} / A$ versus $T$ design curves for the case where $f_{s}$ is reduced to 0.5 . Increasing $f_{S}$ from 2 to 3 , on the other hand, dramatically narrows the range of operating points, as shown by the plot of $P_{E}$ versus $Q_{E}$ given on Fig. 12 (compare to Fig. 7). Assuming that the scaling used for $\tau_{\ell}$ is generally correct, moderate size $\left(P_{E}<1-2\right.$ GWe $)$ and efficient $\left(Q_{E} \geqslant 4-5\right.$ or $E=0.20-0.25$ ) Tormac reactors operating with $I_{W} \leqslant 4 \mathrm{MW} / \mathrm{m}^{2}$ and $T<100 \mathrm{keV}$ are 


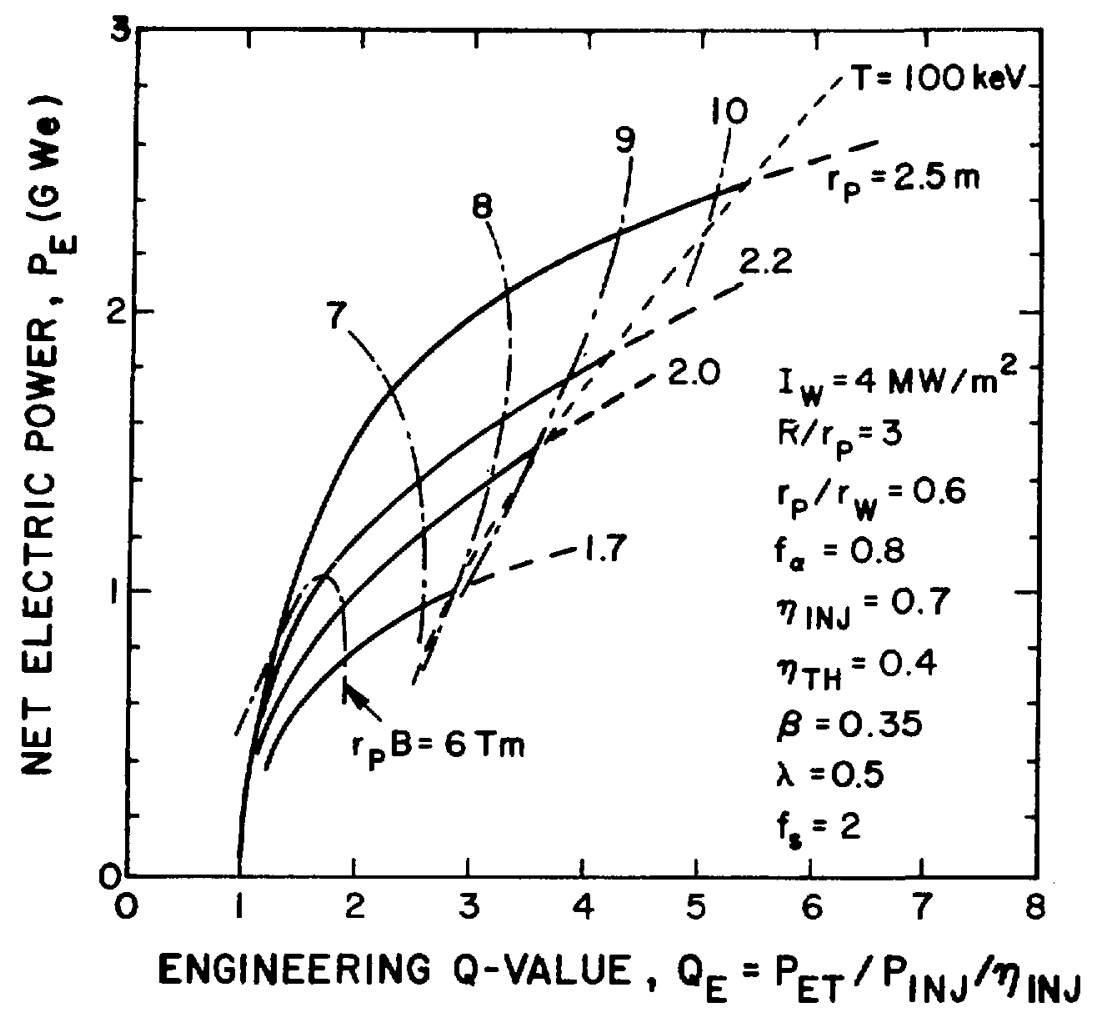

Fig. 8. Effect of decreasing $\beta$ from the reference case (Fig. 7) value of 0.7 to 0.35 on the reactor performance.

possible as long as the sheath thickness does not exceed a few gyroradif. Sheath thickness in excess of a few ion gyroradii (i.e., $f_{s} \geqslant 2$ ) are probably unphysical, 36 however. The sensitivity of these results to the theoretical and experimental basis for $\tau_{\ell}$ clearly dictates an early resolution of the sheath physics for Tormac.

\section{Sensitivity to Tormac Confinement}

The scaling of Tormac reactor parameters has been considered in Ref. 6 and can be summarized as follows:

$$
\begin{aligned}
& T \propto(n \tau)^{2 / 3 /\left(r_{p} / r_{i}\right)^{2 / 3}} \\
& r_{p} \propto(n \tau)^{1 / 3}\left(r_{p} / r_{i}\right) \beta^{2 / 3} / I_{w} 1 / 3
\end{aligned}
$$




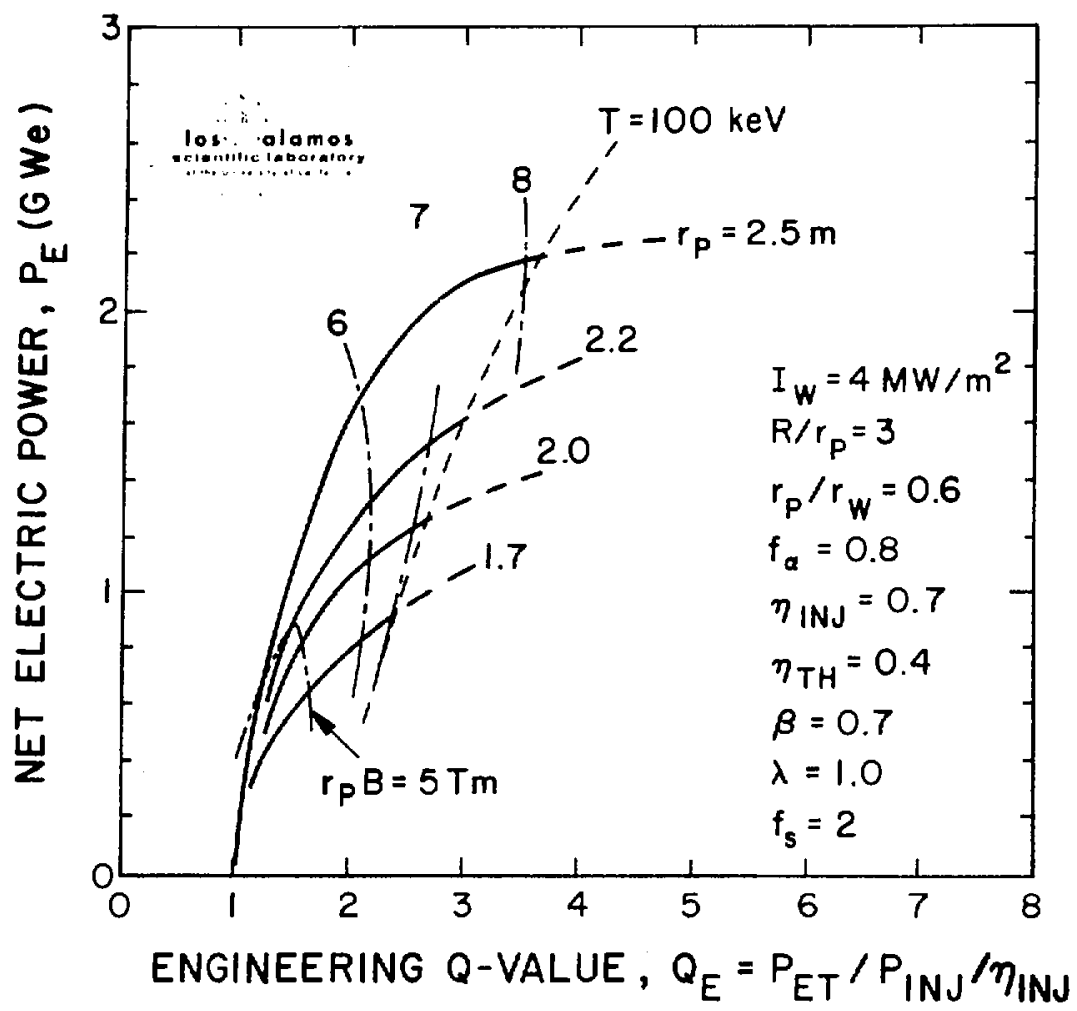

F1g. 9. Effect of 1ncreasing the electron-to-ion temperature ratio $\lambda$ from the reference case (Fig. 7) value of 0.5 to 1.0 .

$$
\begin{aligned}
& B \propto I_{w} 1 / 3 /\left[\left(r_{p} / r_{i}\right)^{1 / 3} 3^{2 / 3}\right] \\
& n \propto I_{w}^{2 / 3 /\left[(n \tau)^{2 / 3} B^{1 / 3}\right]} \\
& P_{E} \propto I_{W}^{1 / 3}(n \tau)^{2 / 3}\left(r_{p} / r_{i}\right)^{2} B^{4 / 3} A,
\end{aligned}
$$

where $r_{i}$ is the ion gyroradius. Considering only the dependence of these parameters on $(n \tau)$, Fig. 13 illustrates the sensitivity of any particular design point obtained from the graphs of the previous section to changes in $(n \tau)$, expressed as the ratio $(n \tau)^{\prime} /(n \tau)$. The dependence of $(n \tau) /(n \tau)$ on the sheath mirror ratio $R_{M}$, as expressed in Eq. (13), is alsc incorporated into 

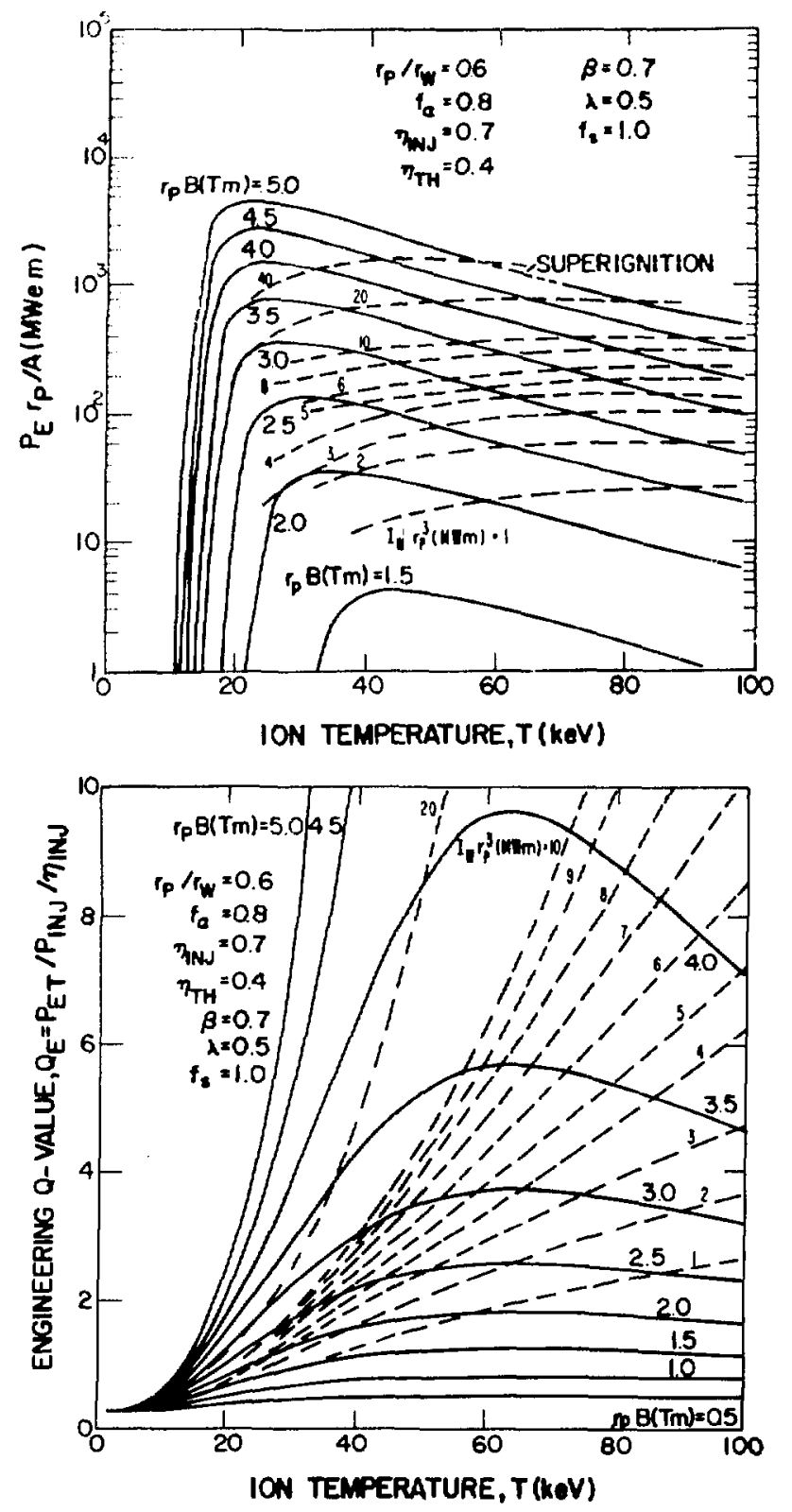

Fig. 10. Dependence of engineering $Q$-value, $Q_{E}$, and net power, $P_{E}$, on ion temperature $T(\mathrm{keV})$ and $r_{\mathrm{p}} B$ for $\mathrm{f}_{\mathrm{S}}=1$ and the other fixed parameters shown (refer to Fig. 6). Lines of constant $\mathrm{I}_{\mathrm{W}^{\mathrm{r}}}^{3}$ are also shown.

Fig. 13 as an independent variable from which an appropriate value of $(n \tau) /(n \tau)$ can be obtained. It may be noted that the dashed line at sheath mirror ratio $R_{M} \simeq 3.162$, corresponding to the LBL/PPPL confinement scaling ${ }^{9}$ as 

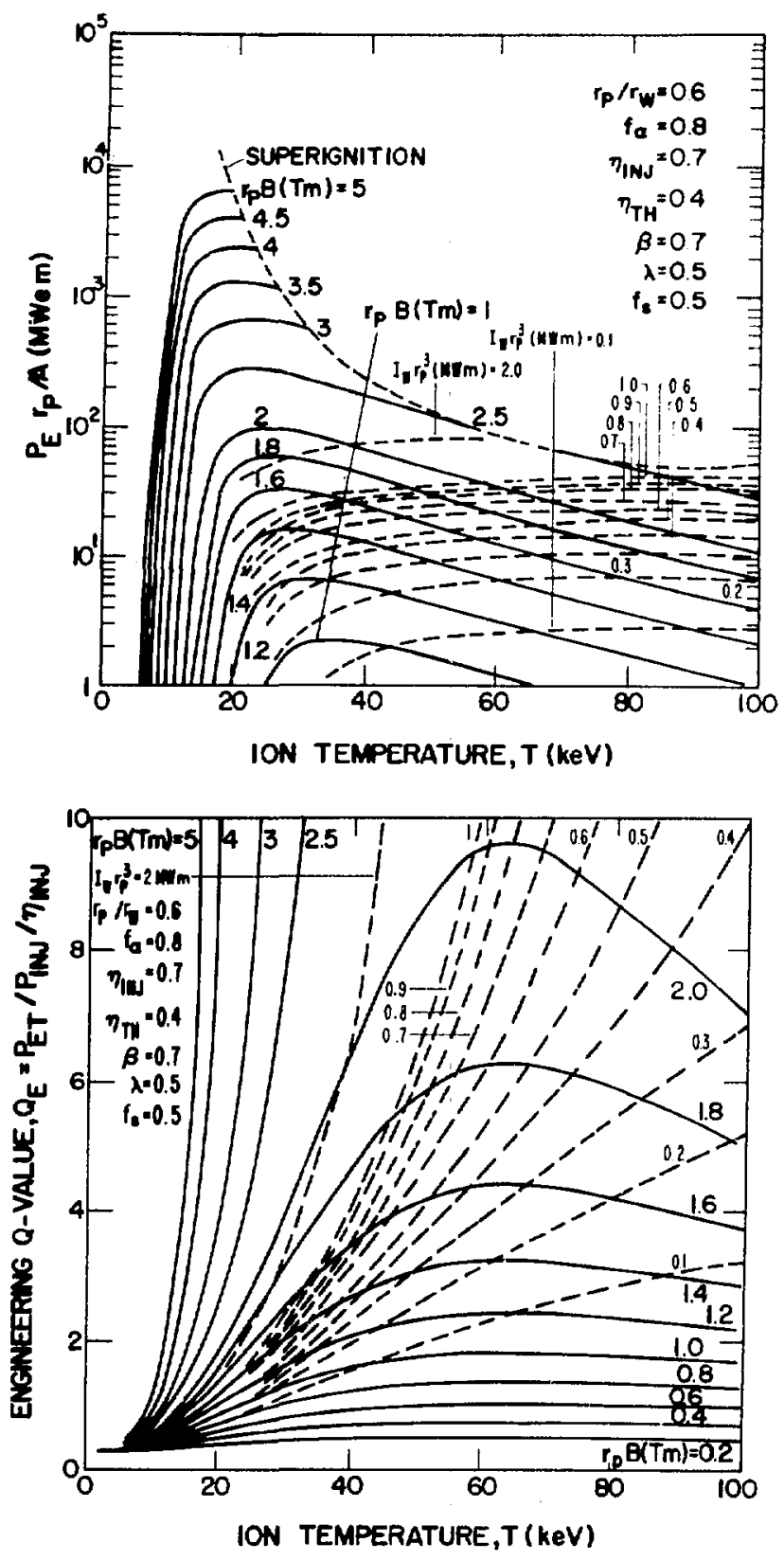

Fig. 11. Dependence of engineering Q-value, $Q_{E}$, and net power, $P_{E}$, on Ion temperature $T(k e V)$ and $r_{B}$ for $f_{s}=0.5$ and the other $f$ ixed parameters shown (refer to Fig. 6). Lines of constant $I_{W} r_{P}^{3}$ are also shown.

obtained from Eq. (9) does not pass through the value $(n \tau)^{\prime} /(n \tau)=1$ because of the factor $\left[\left(R_{M}-1\right) / R_{M}\right]^{1 / 2}$ appearing in Eq. (13). 


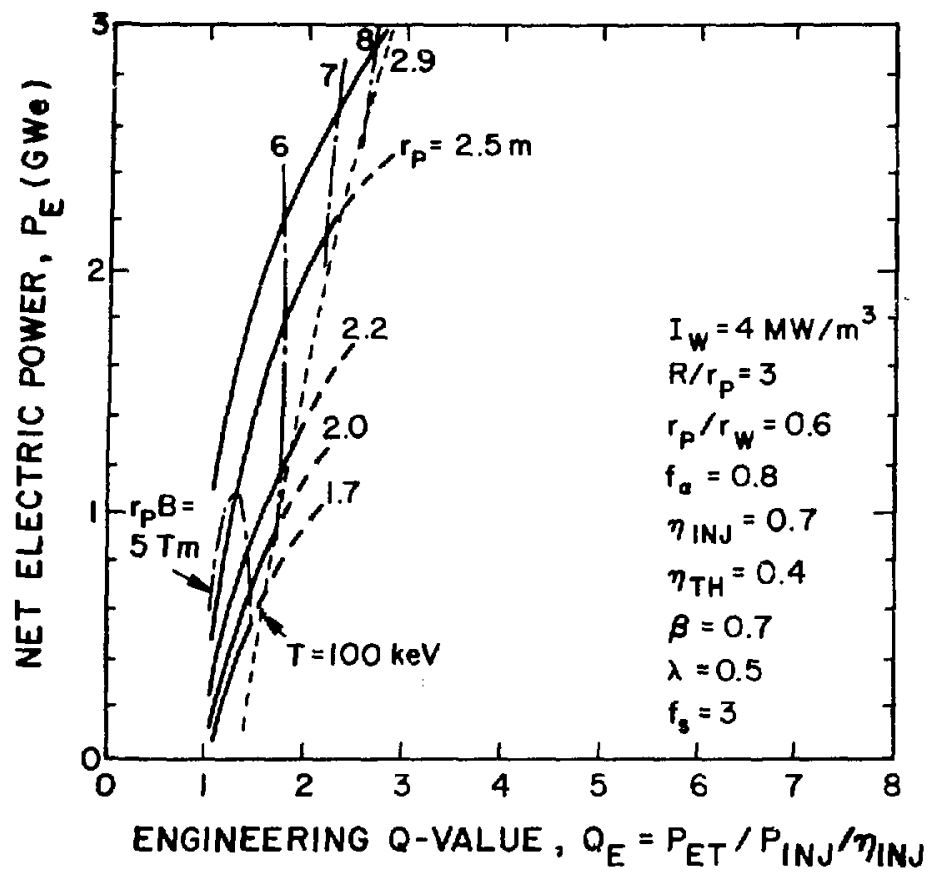

Fig. 12. Effect of increasing the sheath thickness from the reference case (Fig. 7) value from $f_{s}=2$ ion gyroradii to $f_{s}=3$ ion gyroradif.

A ratio $(n t)^{\prime} /(n t)$ greater than unity reflects an improvement in confinement over that used to obtain the parametric design curves of the previous section, while degraded confinement would be indicated by a ratio $(n t)^{\prime} /(n t)$ less than unity. Any particular design point obtained from the previous section; for fixed parameters $\left(r_{p} / r_{1}\right), \beta, A$ and $I_{w}$; may be scaled to a modified operating point using Eqs. (22-26). An 1mprovement in the Lawson parameter results in higher temperature and output power, larger radius and lower density.

\section{Reactor Magnetics Implications}

Both the shape and size of a minimum-B equilibrium plasma as well as the coil configuration required to produce such a plasma are necessary to perform a detalled Tormac reactor study. This information forms the basis for modeling various reactor subsystems such as the blanket, auxilary heating, fueling, and the plasma dump at the cusps. Consequently, the LASL group developed the computational capability to seek equilibrium solutions satisfying the minimum-B condtion. A detailed description of this work is given in the Appendix. The most important result of this work is a 


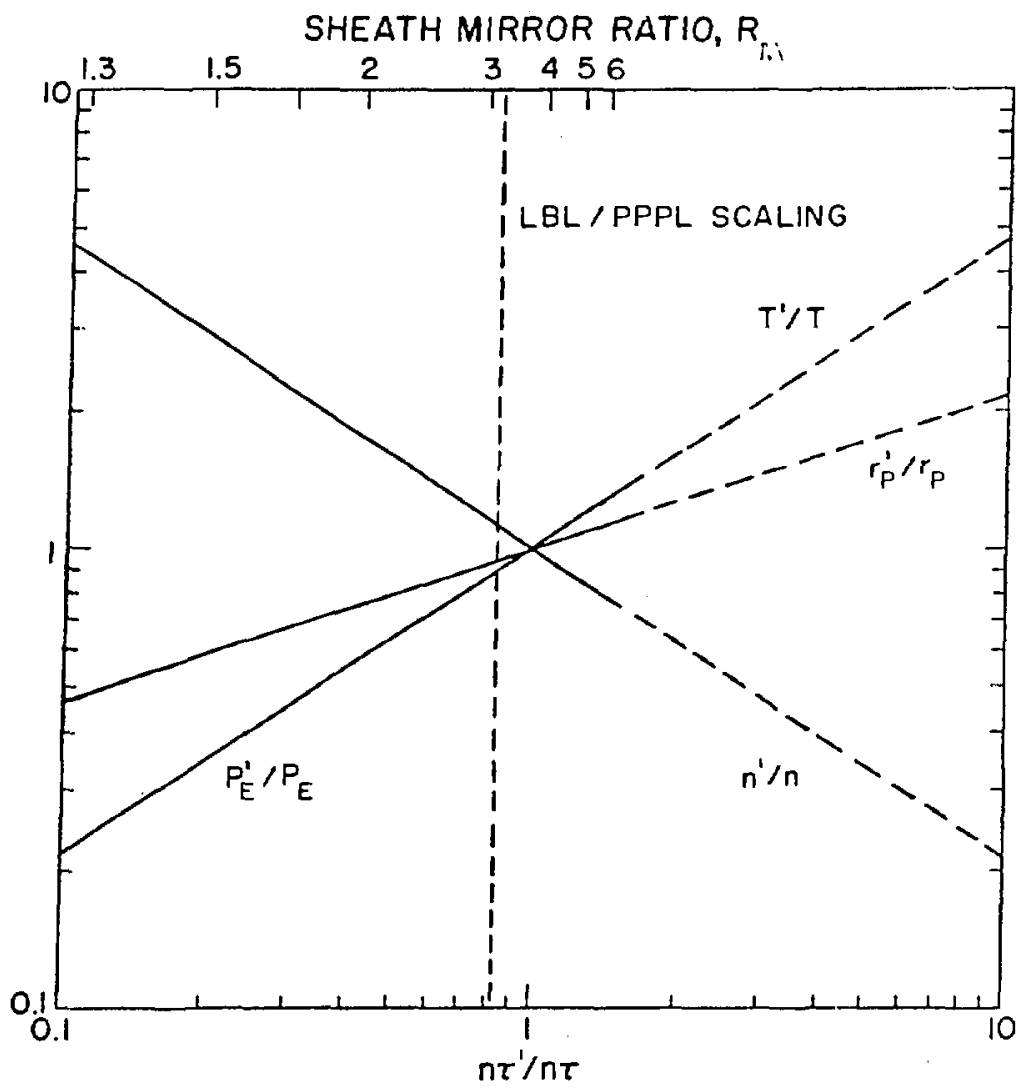

Fig. 13. Scaling of Tormac reactor ion temperature (T), plasma radius ( $r_{p}$ ), density $(n)$, and net electric power $\left(P_{E}\right)$ with Lawson parameter ( $\tau$ ) relative to the classical value. The dependence of $(n \tau)$ on sheath mirror ratio $R_{M}$
using $\mathrm{E}_{q}$. (13) is indicated.

demonstration that a minimum-B equilibrium Tormac plasma can be generated for betas rangling from 1.0 to 0.7 . No longer must the minimum-B magnetic well be referred to as achlevable in princtple.

The coll arrangement necessary to produce such a minimum-B equilibrium plasma at a beta of 0.77 is shown in Fig 4. This particular coil arrangement is noteworthy in that it demonstrates a large volume within the toroidal field coils can be made avaflable in a reactor design. Not only is the distance between the colls and the plasma sufficient for inserting a blanket, but the distance between pololdal fleld colls is sufficient for inserting structural support, performing maintenance, and providing access for auxiliary plasma heating. This working volume is provided at the expense of incurring large currents in the external fleld colls, necessitating superconducting coils. 
A possible negative result also emerged from the magnetics calculations. The position of the flux plume (Figs. 2 and 4 ) and 1 ts assoctated plasma dump was found to be extremely sensitive to coll positions and currents. This facet of the calculation needs more attention to determine if the or $\cdot g$ in of the problem is in the numerical scheme or if Tormac does Indeed have potentially disastrous plasma control problems, particularly during startup and shutdown when currents may be varying. An additional area for concern is whether exercising control of the position of the flux plume will translate into an unrealistic tolerance level in the toroldal field errors.

The reactor implications presented here are predominately qualitative in nature. Time limitations prevented a more quantified approach to the affects of a realistic magnetics design upon reactor performance.

\section{Representative Operating Points}

Using the parametric design figures of Sec. III.D.1, it is possible to determine several representative Tormac reactor operating points, as Indicated on Table IV. The required procedure to be followed in obtaining a Tormac operating point is illustrated by the Reactor A case using Fig. 9 for the assumed sheath-thickness value $f_{s}=2$. A temperature $T=65 \mathrm{keV}$ is first selected. On the lower frame of $\mathrm{Fig} \cdot 10$, a minimally acceptable value of $\mathrm{Q}_{\mathrm{E}}=4.0$ implies that $\mathrm{I}_{\mathrm{w}} \mathrm{r}_{\mathrm{p}}{ }^{3} \sim 70 \mathrm{MWm}$ and $\mathrm{r}_{\mathrm{p}} \mathrm{B} \sim 6.2 \mathrm{Tm}$. For a fixed value of $r_{p} B \sim 6 \mathrm{Tm}, Q_{E}$ exhibits a broad optimum near $T=60 \mathrm{keV}$ which motivates this choice of ion temperature. The upper frame of Fig. 10 is used to obtain the consequent value of $P_{E} r_{p} / A \sim 2.1$ GWe $m$ under these conditions. For $I_{W}=4.0 \mathrm{MW} / \mathrm{m}^{2}$ and $I_{w} r_{p}{ }^{3}=70 \mathrm{MWm}$ the plasma radius becomes $r_{p} \sim 2.6 \mathrm{~m}$ and since $r_{p} B \sim 6.2 \mathrm{Tm}$ the confining fleld is $2.38 \mathrm{~T}$. The product $\mathrm{P}_{\mathrm{e}} / \mathrm{A}$ then becomes $0.81 \mathrm{GWe} / \mathrm{A}$ and for $\mathrm{A}=3$, consistent with Fig. 7, the net electrical output power is $2.42 \mathrm{GWe}$. The major radius $\mathrm{R}=\mathrm{Ar}_{\mathrm{p}}$ is then $7.8 \mathrm{~m}$, which completes the characterization of the operating point.

For the same value of $Q_{E}=4.0$ at $T=65 \mathrm{keV}$ but with a more optimistic cholce of sheath-thickness at $f_{S}=1$, the same procedure is followed using the design curves in Fig. 10. This results in the Reactor B case of Table IV, where the plasma aspect ratio $(A=7.15)$ and major radius $(R=7.6 \mathrm{~m})$ have been selected to correspond more closely to the physical dimensions of the case considered in Table A-I of the Appendix as 11lustrated in Fig. 4. Compared to Reactor A, Reactor B exhibits a lower net power output and indicates the sensitivity of Tormac reactor performance to sheath physics. Because of its lower thermal power and comparable physical size to Reactor A, 32 
Reactor $B$ has a lower overall power density $\left(\mathrm{p}_{\mathrm{TH}}=0.90 \mathrm{MWt} / \mathrm{m}^{3}\right)$. Reactor $\mathrm{C}$ parameters were chosen to compare with the LBL Reactor II parameters of Ref. 45 and give fairly good agreement when an apparent discrepancy in Ref. 45 is corrected [1.e., $\mathrm{P}_{\mathrm{ET}}(1.2)=\eta_{\mathrm{TH}}(0.4) \mathrm{P}_{\mathrm{TH}}(3.0) ; \mathrm{P}_{\mathrm{E}}(0.9)=$ $\left.\left[1-1 / Q_{E}(4.0)\right] P_{E T}(1.2)\right]$, where the total electrical power, $P_{E T}$, is comparable to $P_{G}$ used in Ref. 45. The present model, it may be noted, predicts a modestly higher value for $Q_{E}$. Reactor $D$ on Table IV attempts to take advantage of the favorable mirror confinement scaling by operating at a higher temperature $(T=90 \mathrm{keV})$ and illustrates that higher values of $Q_{E}(e . g ., 5.0)$ are accessible only at higher levels of net output power (> $2.0 \mathrm{GWe}$ ). A reactor with high $Q_{E}$-values at modest power output (Reactors $B$ and $C$ ) requires that the sheath thickness be less than two fon gyroradif.

It is emphasized that the representative design points given in Table IV are not optimized. Also, the sensitivity of reactor performance to the assumed sheath physics is evident. Increases in sheath thickness, as

TABLE IV REPRESENTATIVE TORMAC REACTOR DESIGN POINTS ${ }^{a}$

\begin{tabular}{lcccc} 
& Reactor $\mathrm{A}$ & Reactor B & Reactor C & Reactor D \\
\cline { 2 - 3 } & 2 & 1 & 1 & 2 \\
$\mathrm{f}$ & 65 & 65 & 50 & 90 \\
$\mathrm{~T}(\mathrm{keV})$ & 2.6 & 1.06 & 1.5 & 2.33 \\
$\mathrm{r}_{\mathrm{p}}(\mathrm{m})$ & 7.8 & 7.6 & 6.0 & 7.0 \\
$\mathrm{R}(\mathrm{m})$ & 3.0 & 7.15 & 4.0 & 3.0 \\
$\mathrm{~A}=\mathrm{R} / \mathrm{r}_{\mathrm{p}}$ & 1041 & 169 & 266 & 750 \\
$\mathrm{~V}_{\mathrm{p}}\left(\mathrm{m}^{3}\right)^{\mathrm{b}}$ & 2.38 & 3.0 & 2.3 & 3.0 \\
$\mathrm{~B}(\mathrm{~T})$ & 8.08 & 2.47 & $3.44(3.0)^{\mathrm{d}}$ & 7.24 \\
$\mathrm{P}_{\mathrm{TH}}(\mathrm{GWt})$ & 3.23 & 0.99 & $1.38(1.2)^{\mathrm{d}}$ & 2.90 \\
$\mathrm{P}_{\mathrm{ET}}(\mathrm{GWe})$ & 2.42 & 0.74 & $1.07(0.9)^{\mathrm{d}}$ & 2.32 \\
$\mathrm{P}_{\mathrm{E}}(\mathrm{GWe})$ & 4.0 & 4.0 & $4.5(4.0)^{\mathrm{d}}$ & 5.0 \\
$\mathrm{Q}_{\mathrm{E}}$ & 1.13 & 0.90 & $1.16(1.01)^{\mathrm{d}}$ & 1.29 \\
$\mathrm{P}_{\mathrm{TH}}\left(\mathrm{MWt} / \mathrm{m}^{3}\right)^{\mathrm{c}}$ & & & &
\end{tabular}

\footnotetext{
a Fixed parameters: $\beta=0.7, I_{W}=4 \mathrm{MW} / \mathrm{m}^{2}, \lambda=0.5, r_{p} / r_{w}=0.6$, $n_{\text {INJ }}=0.7, f_{\alpha}=0.8, n_{T H}=0.4$.

b Plasma volume $\left(2 \pi^{2} \mathrm{Rr}_{\mathrm{p}}^{2}\right)$.

c Thermal power density assuming $2.5 \mathrm{~m}$ thick blanket/coll structure.

d Comparable results from Ref. 45 .
} 
reflected by $f_{S}=\Delta_{S} / r_{1}$, degrade the Tormac reactor performance $\left(Q_{E}, P_{E}\right)$, as do decreases in the alpha-particle trapping efficiency $f_{\alpha}$. Thie sensitivity of reactor performance to sheath thickness is demonstrated explicitly in Fig. 14 for a few typical operating points. Lower recirculating power fractions, $1 / Q_{E}$, can be achleved by moving along the iso-r ${ }_{p}^{3} I_{w}$ curves (1.e., Fig. 6) to higher temperatures and $r_{p} B$ values; more efficient, low-power systems result by allowing increased wall loading, $I_{w}$, or increased magnetic flelds, $B$. Generally, moderate decreases in $\beta$ can be offset by modest Increases in $B$, which for the sample cases is already acceptably small.

IV. CONCLUSIONS AND EVALUJATION

Quantification of the general sensitivity of an idealized (stable, structureless, steady-state plasma) Tormac reactor to key plasma parameters represents the major goal of this Level III study; the development of a specific operating point is not intended here. Although moderate decreases in

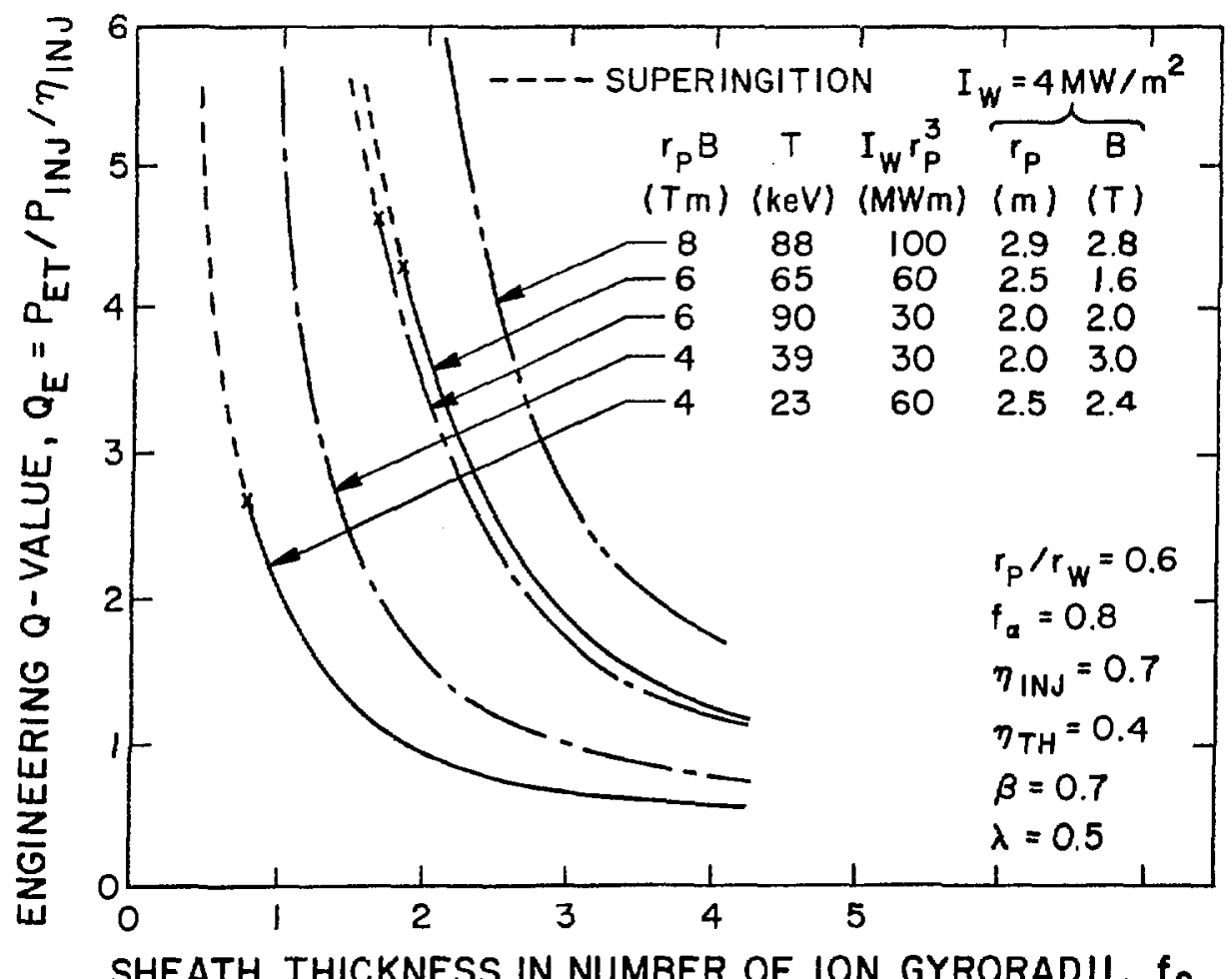

SHEATH THICKNESS IN NUMBER OF ION GYRORADII, $f_{s}$

F1g. 14. Dependence of Tormac reactor performance on Tormac sheath thickness for the optimistic design points summarized on Fig. 6 . 
beta have little effect on the reactor performance, other than requiring an increase in the already low to modest magnetic flelds, increases in $\lambda=T_{e} / T_{i}$ may limit $Q_{E}$ for the ion temperaure range considered. The effects of changes in sheath parameters (1.e., $g, f_{s}, n / n_{s}$ and $\tau_{\Theta 11} / \tau_{1 e}$ ) and the alpha-particle trapping efficiency, $f_{\alpha}$, are additional variables upon which the reactor performance will crucially depend. The sensitivity of a realistically constrained operating point to the sheath physics has been noted. This finding strongly points out the need for a better theoretical and experimental understanding of the sheath physics. On the basis of this preliminary scoping study future Tormac reactor studies should address the following issues:

- The feasibility of generating a model for the sheath physics in a reactor regime that is more quantitative than the one used heretofore should be examined.

- A time-dependent pressure-balance thermonuclear burn code that is based on a realistic analytic model of fleld, density, temperature profiles should be developed. With this burn code the following issues could be assessed:

- examine the feasibility of steady-state operation (i.e., poloidal flux requirements, bootstrap currents, etc.)

- examine thermal stability

- better quantify the interplay between cusp geometry, field/conductor configuration, and plasma equilibrium

- examine analytically geometry effects on plasma reactivity and wall loading

- develop a more detalled reactor energy balance

- examine the efficiency of neutral-beam trapping

- The physics and technology of achieving the Tormac minimum-B configuration (1.e., startup) should be addressed in conjunction with a realistic burn mode1.

- A more detafled layout of first-wa11, blanket, shield and magnet, and infect or geometries/arrangement should be generated.

- The conclusions of previous assessments of the Tormac reactor concept, 43-45 particularly those 45 which attempt to "score" reactor desirability on the basts of particular design parameters, should be reevaluated.

Although the startup method for a Tormac reactor could not be quantitatively elucidated, the reactor advantages of steady-state operation and natural divertors were neither verifled nor disproved. An ignited mode of operation does not appear likely, even for the more optimistic plasma parameters (Fig. 6), without very large plasma dimensions, total power output, and wall loadings. Although the economic outlook for a $Q_{E}=4-5$ Tormac generating net power at a level of a few GWe may be acceptable, such a reactor would require hundreds of $\mathrm{MW}$ of steady-state neutral beam or other plasma sustenance power. This marginal prognosis rapidly degrades as the sheath thickness broadens beyond a few Ion gyroradil. Generally, the optimistic scaling adopted by this study predicts that if a means could be found to scart 
and sustain a steady-state Tormac reactor, recirculating power fractions below $\sim 0.20$ cannot be achieved without generating multigigawatt net electric output. Given a favorable resolution of the sheath confinement time and associated micro-stability, the establishment of the bicusp configuration by means other than those associated with rapld (high-voltage) implosion heating is simply not known. Since most of the power delivered to the plasma must exit the system through the cusps, the power densities in these "natural divertors" for a $Q_{E}=4-5$ system could be significant; typically, at least 6-7\% of the total thermal output would pass through these cusp regions for a $Q_{E}=4-5$ system, and either a considerable increase in wall area or a surface tolerance to high power densities will be required.

The results of high-beta magnetics/equflibrium calculations (Appendix) Indicate that some semblance of a "minimum-B" configuration can be obtained with 10 pololdal colls that are suitably arranged to permit the placement of an intervening $1.5-\mathrm{m}-\mathrm{thick}$ blanket/shield structure. The toroidal coil structure will force the system to relatively low aspect ratio from the viewpoint of these coll sets, and flelds at the coll windings in excess of $8 T$ will be required. Nevertheless, the poloidal/toroldal coll systems appear to be relatively open and accessible from the viewpoint of blanket/shield module replacement, neutral-beam Injection, and cusped divertor/mirror auxiliaries. These latter issues, however, should be examined by a more detailed study that allows the development of an engineering layout of the Tormac reactor. ACKNOWL EDGMENTS

The authors gratefully acknowledge helpful discussions with M. A. Levine, I. G. Brown, H. Berk (LBL) and R. L. Hagenson (LASL). In addition, R. W. Moses, D. C. Barnes, J. U. Brackbil1 and M. A. Mostrom (LASL) and A. Andrade of the University of Michigan are acknowledged for their assistance and advice. 


\section{APPENDIX: MAGNETICS DESIGN}

Upon completion of the parametric scoping study that has served as the basis of this report, it became evident that the Tormac reactor study could not proceed until the shape and size of a minimum-B toroidal bicusped plasma was estimated. The plasma/coil(s) configuration required to produce a minimum-B equilibrium is needed before first-wall/blanket/shield, neutral-beam, fueling, cusp energy-rejection, and pololdal-field-coil (PFC)/toroidal-field-coll (TFC) systems could be characterized. Furthermore, the magnetics design would also be required before a more detailed plasma (sheath and associated energy-balance) model could be developed. Consequently, an attempt was made to define better the equilibrium Tormac reactor plasma. After consultation with the LBL Tormac group, it became evident that equilibrium calculations of the Tormac experimental plasma were inapplicable and unavailable to the reactor study. Consequently, the LASL group commenced an independent search for a Tormac equilibrium. Initial attempts to adopt well-proven toroldal equilibrium codes to the unique, open-field Tormac configuration proved unfeasible. The state-of-the-art computation developed by the LASL group in the course of this study is described in this Appendix. Unfortunately, the study period was concluded before results of the Tormac equilibrium calculation became available to further the overall study effort. Nevertheless, the computations are sufficiently complete to lend a new dimension and insight to the Tormac reactor problem.

\section{A. Calculationa1 Procedure}

The coil and plasma model developed in the course of this study computes only the poloidal magnetic field and flux explicitly from a discrete, point loop current representation of both external poloidal field coils and toroidal plasma sheath currents. This model is shown schematically in Fig. A-1. The toroidal magnetic field is postulated to vary inversely with the major radius. Furthermore, a pololdal sheath current is postulated that cancels all or some fraction of the external toroldal magnetic field within the plasma; the degree of toroidal field cancellation is dictated by the assumed beta value.

The calculation begins with the specification of the toroidal field, the position of the external poloidal field coil (PFC) set, and the plasma shape, thereby yielding the locations of the toroidal sheath currents. The toroidal plasma sheath currents are determined from an MHD pressure balance. The external poloidal field coil currents are then derived from the poloidal flux 


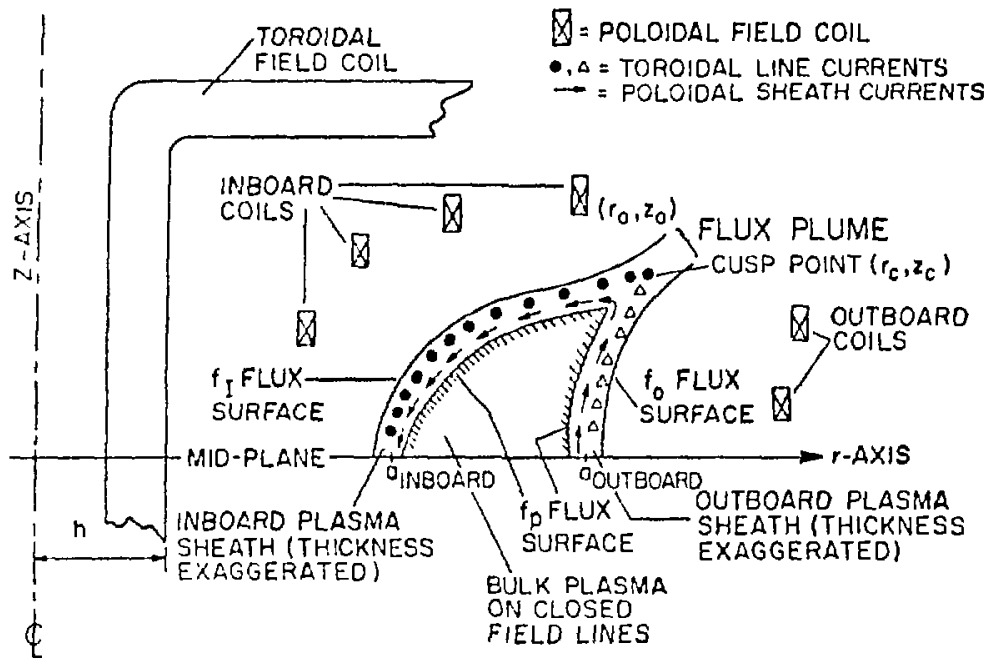

TORMAC FIELD / PLASMA MODEL

Fig. A-1. Schematic diagram of field/coll/plasma cross-section used by the Tormac reactor equilibrium and minimum-B calculation.

conditions that are characteristic of Tormac. The above procedure is repeated as the plasma surfaces and/or the external coll set are moved in an effort to secure the correct value of the total magnetic fleld along the plasma surface. The results obtained are subsequently checked for the minimum-B condition and engineering desirability (i.e., coll locations and current desitittes). The details of the calculations and some interim results are presented below.

B. Calculational Model

An arbitrary shape function of the form

$$
z(r)=z_{c}\left\{\frac{r-a}{r_{c}-a}\right\}^{p}+\sum_{n=1}^{N_{t}} A_{n} \sin \left\{n \pi\left(\frac{r-a}{r_{c}-a}\right)\right\}
$$

Is used to represent either the inboard or outboard plasma surfaces in the upper half-plane; the lower half-plane is obtalned by reflecting the upper half-plane about the mid-plane. Figure A-1 illustrates this geometry and some notation. The intersection of this generalized plasma surface with the mid-plane is denoted by " $a$ " in $E q \cdot(A-1)$, the cusp coordinates are given by $\left(r_{c}, z_{c}\right)$ and $\mathbb{N}_{t}(=4)$ is the number of terms employed in the sinusoidal 
expanston. In order to obtain well-behaved plasma surfaces (e.g., only one intersection with the mid-plane in the interval a $r<r_{c}$ ) the following constraints are imposed upon Eq. (A-1)

$$
0.0<p<1.0
$$

$$
A_{n}>A_{n+1} / 10
$$

An additional constraint required for equilibrium at the cusp is that the Inboard and outboard surfaces have the same slope at the cusp. The plasma shape is then determined by specifying $r_{c}, z_{c}$, a and a set of $A_{n}$ 's for each surface.

The distribution of the toroldal sheath currents along the plasma surface can be made uniform. The procedure uses the following equation for a differential element ds along the surface

$$
d s=d r \sqrt{1+\left\{\frac{d z(r)}{d r}\right\}^{2}}
$$

By transforming Eq. $(A-4)$ into a finite difference form

$$
\Delta s=\left(r_{1}-r_{1-1}\right) \sqrt{1+\left[\frac{d z\left(r_{i}\right)}{d r}\right]^{2}},
$$

a scheme can be devised for generating uniformly distributed sheath currents. A set of $r_{1}^{\prime}$ 's is initially chosen on the interval $a<r<r_{c}$ with the first and last elements of this set always taken as $r_{1}=a$ and $r_{N_{p}}=r_{c}$, respectively. The corresponding set of derivaties, $\mathrm{dz}\left(\mathrm{r}_{i}\right) / \mathrm{dr}$, are then calculated. The pololdal coil spacing $\Delta$ s is fixed by the relationship

$$
\Delta s=\frac{1}{N_{p}} \sum_{1=2}^{N_{p}}\left(r_{1}-r_{1-1}\right) \sqrt{1+\left\{\frac{d z\left(r_{1}\right)}{d r}\right\}^{2}},
$$


where $N_{p}$ is the number of pololdal current elements. Having determined $\Delta s$ and the set of $\mathrm{dz}\left(\mathrm{r}_{1}\right) / \mathrm{dr}, \mathrm{Eq} \cdot(\mathrm{A}-5)$ is used to generate a second set of $r_{1}^{\prime} \mathbf{s}$. This procedure is repeated unt1l the spacing between colls varies within an acceptable tolerance.

The set of point currents, $I^{\prime}$, simulate the toroldal component of the plasma sheath current and are determined from an equilibrium pressure balance of the form

$$
p+B_{I}^{2} / 2 \mu_{0}=B_{0}^{2} / 2 \mu_{0},
$$

where $p$ is the pressure exerted by the plasma, $B_{I}$ is the field inside of the plasma sheath, and $B_{0}$ is the field outside of the plasma sheath. Assuming that the Tormac concept excludes all pololdal magnetic field from the inside of the plasma sheath, ${ }^{B}$ I corresponds to whatever toroldal magnetic field may penetrate the sheath and is determined by the assumed beta $\left(\beta \equiv 2 \mu_{0} p / B_{0}^{2}\right)$. The external toroidal field is approximated by

$$
B_{\phi}(r)=B_{\phi C} h / r \text {, }
$$

where $B_{\phi c}$ is the coroidal field strength at the inside coil surface of the inboard leg located at $r=h$. The internal toroidal magnetic field is reduced by the presence of a poloidal plasma sheath current, $I_{p}$, and is approximated by

$$
B_{I}(r)=\left(B_{\phi c} h-\mu_{o} I_{p} / 2 \pi\right) / r
$$

The Internal plasma field, $B_{I}$ is zero for the case where $\beta=1$ and the value of $I_{p}$ is determined by $\mathrm{Eq} \cdot(\mathrm{A}-9)$. For cases where $\beta<1$, a value of $I_{p}$ is assumed and $B$ must be calculated by a surface average given by

$$
\beta=\int \beta(s) \mathrm{ds} / \int \mathrm{ds},
$$


where $B(s)$ is the local beta measured at some distance $s$ along the surface, and $d s$ is defined by Eq. $(A-4)$. By fixfing $p, I_{p}, B_{\phi c}$, and h, all magnetic fields are determined. In particular, the external poloidal magnetic field, $\mathrm{B}_{\odot}(\mathrm{r})$, is given by -

$$
B_{\ominus}(r)=\sqrt{2 \mu_{O} P+B_{I}^{2}(r)-B_{\phi}^{2}}(r)
$$

The pololdai fleld, $B_{\odot 1}$ generated by a single point current, $I_{i}$, of the set of toroidal sheath currents is given by Ampere's law as

$$
B_{\Theta i}=\mu_{0} I_{i}^{\prime} / 2 \Delta s_{i}
$$

where $\Delta s_{1}$ is the local coll spacing. In order to exclude the poloidal field from the inside of the sheath, $B_{\Theta}$ must equal $2 B_{\Theta I}$. The toroidal sheath currents for this case are given by

$$
I_{i}^{\prime}=\left(\Delta s_{1} / \mu_{0}\right) \sqrt{2 \mu_{0} p+B_{I}^{2}(r)-B_{\phi}^{2}}(r)
$$

The external pololdal fleld coll currents are derived from poloidal flux conditions imposed upon the sheath boundaries. The definition of the numerical sheath boundaries employed in these calculations differs from the normal Tormac concept of a sheath width of a few ion gyroradil. Because discrete colls are used to simulate the toroidal sheath currents, a numerical sheath boundary must be located a sufficient distance from these colls to assure that field variations arising from individual coils are negligible. The numerical sheath width adopted here is four times the average coil spacing, $\Delta s$ of $\mathrm{Eq}$. (A-6), with the sheath currents centered within the sheath.

The Imposed poloidal flux conditions are dictated by requiring that poloidal flux lines conform to the outer plasma surface and be of constant value Internal to the plasma. These conditions are imposed numerically by requiring (refer to Fig. A-l) that:

- the poloidal flux at every point on the outer plasma sheath surface at the inboard plasma side is a constant, $f_{I}$.

- the poloidal flux at every point on the outer sheath surface at the outboard plasma side is a constant, $\mathrm{f}_{\mathrm{O}^{*}}$ 
- the pololdal flux at every point on the inner sheath surface at both the inboard and outboard regions of the plasma is a constant, $f_{p}$.

In order to calculate the pololdal flux through a disk of radius $r_{0}$ at a height $z_{o}$ above the mid-plane from all the pololdal field colls, a Green's function $G\left(r_{0}, z_{0} \mid r_{1}, z_{1}\right)$ has been defined. This function calculates the poloidal flux resulting from two toroldal currents of magnitude $I_{1}$ that are symmetrically positioned at $z_{i}$ above and below the mid-plane with radius $r_{i}$. An array of $\mathrm{N}_{\mathrm{E}}$ external pololdal field coll locations is spectifed in addition to the known locations of $\mathrm{N}_{\mathrm{p}}$ pololdal field coils internal to the plasma sheath on both the inboard and outboard plasma sides. Following this procedure, the poloidal flux at $\left(r_{0}, z_{0}\right)$ is given by

$$
F\left(r_{0}, z_{0}\right)=\sum_{i=1}^{N_{E}} G\left(r_{0}, z_{0} \mid r_{i}, z_{i}\right) I_{i}+\sum_{i=1}^{N_{P}} G\left(r_{o}, z_{o} \mid r_{i}, z_{i}\right) I_{i} .
$$

Similarily, expressions for the $r$ and $z$ components of the poloidal magnetic field, $B_{Y}\left(r_{0}, z_{0}\right)$ and $B_{z}\left(r_{0}, z_{0}\right)$, respectively, may be written as follows

$$
\begin{aligned}
& B_{r}\left(r_{0}, z_{0}\right)=\sum_{i=1}^{N_{E}} H_{r}\left(r_{0}, z_{0} \mid r_{i}, z_{i}\right) I_{i}+\sum_{i=1}^{N} H_{r}\left(r_{0}, z_{0} \mid r_{1}, z_{i}\right) I_{i}^{\prime} \\
& B_{z}\left(r_{0}, z_{0}\right)=\sum_{i=1}^{N_{E}^{E}} H_{z}\left(r_{0}, z_{0} \mid r_{i}, z_{i}\right) I_{i}+\sum_{i=1}^{N} H_{z}\left(r_{0}, z_{0} \mid r_{i}, z_{i}\right) I_{i}^{\prime} .
\end{aligned}
$$

Expressions for the Green's functions, $G\left(r_{0}, z_{0} \mid r_{1}, z_{i}\right), H_{r}\left(r_{0}, z_{0} \mid r_{i}, z_{i}\right)$, and $H_{2}\left(r_{0}, z_{0} \mid x_{1}, z_{1}\right)$, are obtained by factoring out the current, $I$, in the expressions for $2 \pi r A_{\phi}, B_{r}$, and $B_{z}$, respectively, of Ref. 46 .

Upon evaluating the flux at each of the $N_{p}$ sheath surface points employed in the solution of $\mathrm{Eq}$. (A-13), thereby eliminating duplicate calculations, the following sets of equations for the external pololdal field coil currents, $I_{i}$, are obtained

$$
\begin{array}{ll}
f_{I}-G_{p}\left(r_{k}, z_{k}\right)=\sum_{i=1}^{N_{E}} G\left(r_{k}, z_{k} \mid r_{i}, z_{i}\right) I_{i} & \left(k=1, \ldots, N_{p}\right) \\
f_{0}-G_{p}\left(r_{\ell}, z_{\ell}\right)=\sum_{i=1}^{N_{E}^{E}} G\left(r_{\ell}, z_{\ell} \mid r_{i}, z_{i}\right) I_{1} & \left(l=1, \ldots, N_{p}\right)
\end{array}
$$




$$
f_{p}-G_{p}\left(r_{m}, z_{m}\right)=\sum_{1=1}^{N_{E}} G\left(r_{m}, z_{m} \mid r_{1}, z_{i}\right) I_{1} \quad\left(m=1, \ldots, N_{\alpha}\right),
$$

where

$$
G_{p}\left(r_{j}, z_{j}\right)=\sum_{1=1}^{N} G\left(r_{j}, z_{j} \mid r_{1}, z_{i}\right) I_{i},
$$

and $N_{\alpha}<2 N_{p}$ is the number of points on the Inner sheath surfaces between the midplane and their intersection point near the cusp. Eliminating the flux constants $f_{I}, f_{0}$, and $f_{p}$ from Eqs. $(A-17),(A-18)$, and $(A-19)$, the following set of equations is obtained.

$$
\begin{aligned}
& G_{p}\left(r_{k^{\prime}}, z_{k^{\prime}}\right)-G_{p}\left(r_{k}, z_{k}\right)= \\
& \sum_{1=1}^{N_{E}}\left(G\left(r_{k}, z_{k} \mid r_{1}, z_{1}\right)-G\left(r_{k^{*}}, z_{k} \cdot \mid r_{1}, z_{1}\right)\right) I_{1} \quad\left(k=1, \ldots, N_{p}-1\right) \\
& G_{p}\left(r_{\ell^{e}}, z_{\ell^{\prime}}\right)-G_{p}\left(r_{\ell}, z_{\ell}\right)= \\
& \sum_{1=1}^{N_{E}}\left(G\left(r_{\ell}, z_{\ell} \mid r_{1}, z_{1}\right)-G\left(r_{\ell^{\prime}}, z_{\ell^{\prime}}, \mid r_{1}, z_{1}\right)\right) I_{1} \quad\left(\ell=1, \ldots, N_{p}-1\right) \\
& G_{p}\left(r_{m^{\prime}}, z_{m^{\prime}}\right)-G_{p}\left(r_{m}, z_{m}\right)= \\
& \sum_{1=1}^{N} E\left(G\left(r_{m}, z_{m} \mid r_{1}, z_{1}\right)-G\left(r_{m}^{\prime} z_{m}^{\prime} \mid r_{i}, z_{1}\right)\right) I_{1} \quad\left(m=1, \ldots, N_{\alpha^{-1}}\right)
\end{aligned}
$$

To replace the three equations eliminated above, the following set of equations for the pololdal fleld is added for three locations on the sheath surface in the midplane

$$
2 \mu_{o} p+B \frac{1}{I}\left(r_{k^{\prime}}\right)-\left(B_{\phi c} h / I_{k^{\prime}}\right)^{2}=\sum_{I=1}^{N} H_{z}\left(r_{k^{\prime}}, z_{k} \cdot \mid r_{1}, z_{i}\right) I_{i} \cdot\left(k^{\prime}=1,2,3\right)(A-24)
$$


Equations $(A-21),(A-22),(A-23)$, and $(A-24)$ are reduced to a set of $N_{E}$ equations by the least squares technique. 47 The set of $N_{E}$ equations may in turn be solved for the set of $\mathrm{I}_{1}$ by standard matrix inversion techniques. The determination of the set of $I_{1}$ completes this stage of the calculation.

The final stage of the calculation returns to the problem of obtaining the equilibrium poloidal field on the outer plasma surface [Eq - (A-11)]. This solution can be accomplished through the movement of the pololdal fleld colls. The coil movement is restricted here to either the external poloidal fleld coll set or the toroidal sheath currents. The toroldal sheath currents are moved collectively as the plasma surface is either shifted or 1ts shape altered by changing the coefficients of $\mathrm{Eq} \cdot(\mathrm{A}-1)$. The movement of the poloidal colls is performed by an optimization program based on an algorithm developed separately. 48 The optimization program employes only the techniques of "steepest descent" and "adaptlve creeping" from the algorithm. Briefly, the steepest descent technique pursues an optimum along the path of the largest gradient and adaptive creeping is used to avold obstacles such as forbidden parameter regions. Reference 48 gives a more detalled explanation. A means for simulating higher order terms (i.e., $\partial^{2} f(\vec{x}) / \partial x_{1} \partial x_{2}$ ) has been added to the gradient calculation. This addition has proven to be very helpful. The figure of merit, $F$, that is minimized is defined by

$$
F=\sum_{1=1}^{N}\left|1.0-\left[B_{c}\left(r_{i}, z_{1}\right) / B_{0}\left(x_{1}, z_{1}\right)\right]^{2}\right|,
$$

where $B_{c}$ is the calculated magnetic field on the outer sheath surface, $B_{0}$ is the equilibrium magnetic field given by Eq. (A-7), and $N_{x}$ is the number of variables employed in the optimization. Because of the discrete cotil approximation to a sheath current, $F$ cannot be made smaller than the inverse of the number of colls used to approximate a sheath current (1.e., $1 / \mathrm{N}_{\mathrm{p}}$ ). Consequently, when an optimization yields an $F$ that is of the order of $1 / N_{P}$, the resulting solution is taken as the equilibrium solution. 


\section{Results of Minimum-B Search}

The equilibrium solutions obtained with the methodology described in Sec. V.B are not necessarily minimum-B solutions. For $B=1$ cases a mod-B contour line will conform to the plasma surface within the error margins of the numerical calculation. The existence of such a contour line, however, does not insure a minimum-B configuration. An example of this point is found in the case described in Figs. A-2 to A-5. From the flux contour plot of Fig. A-2, contours of constant flux are found to conform to the outer sheath surface, which is drawn as a dotted line in Fig. A-2; the flux criteria of Tormac are thereby met. Through the movement of the plasma surface, the calculation of the magnetic field on the outer sheath surface succeeded in

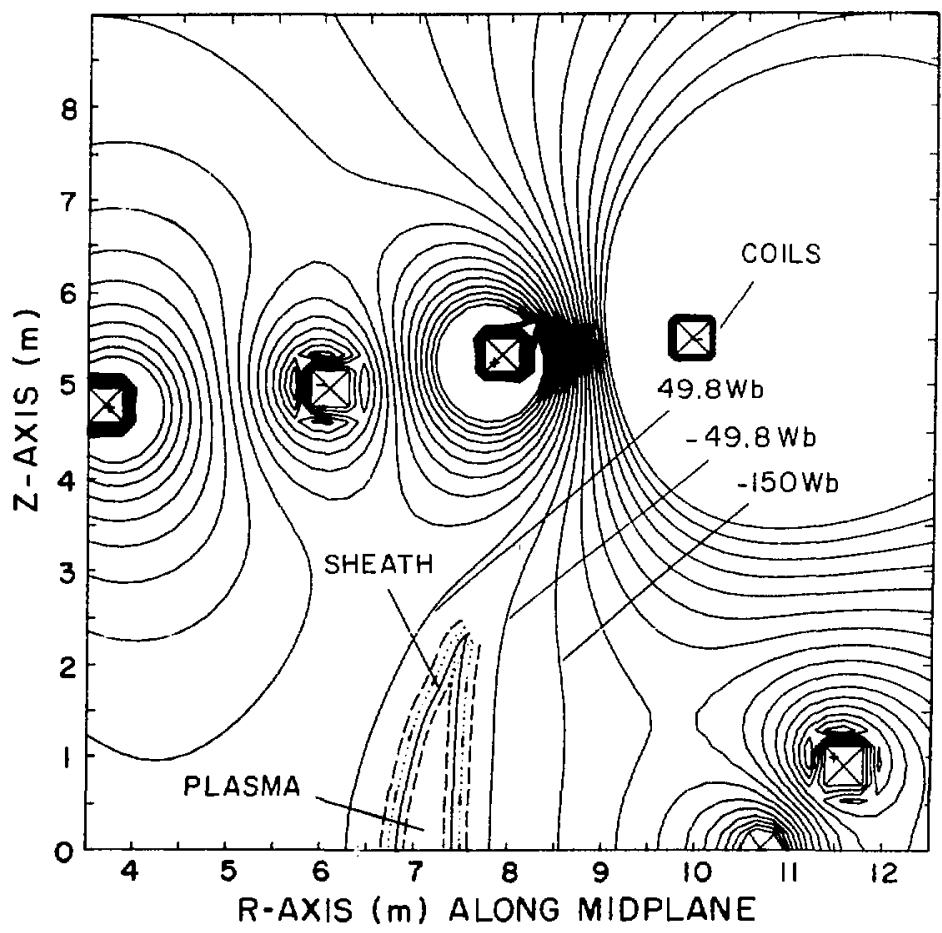

F1g. A-2. Magnetic flux contours for a $B=1$ equilibrium solution which is not a minimum-B solution. Contour lines are incremented in steps of $\sim 100 \mathrm{~Wb}$. The convention of encasing external poloidal field colls in square boxes is used through this Appendix. A plus or minus sign within a box denotes current Into and out of the paper, respectively. The inner and outer numerical sheath boundaries are denoted by dash-dot-lines and dotted lines respectlvely. The sheath currents are distributed along the solld line half-way between these two lines. 


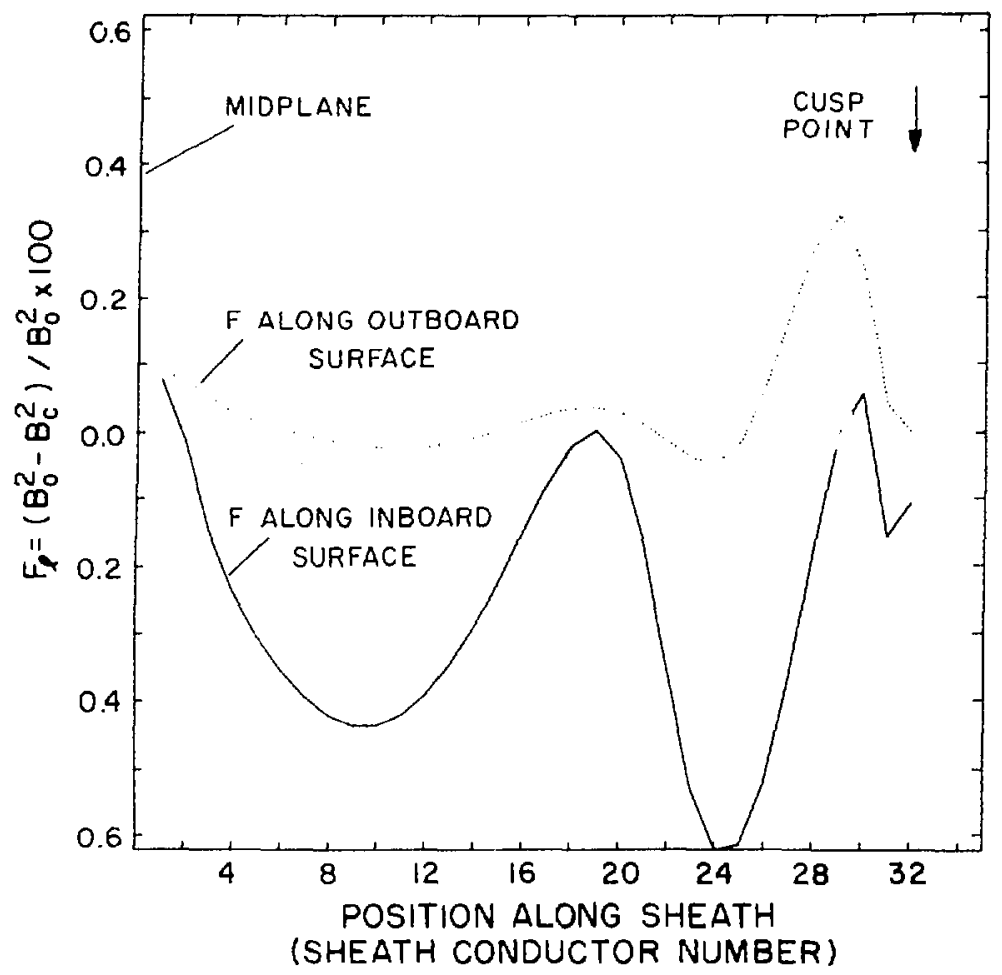

Fig. A-3. A plot of the local figure of merit $F_{l}$ as a function of coll position along the surface. Sheath conductor number one is on the midplane, and number thirty two is located at the cusp.

obtalning the equilibrium fleld value to within better than $1 \%$, as is seen in Fig. A-3. Examination of mod-B contours taken along the midplane, as shown in Fig. A-4, demonstrates the exclusion of the magnetic field from within the $B=1$ plasma. From the results presented in Figs. A-3 and A-4, this case is concluded to comply with the MHD equilibrium jump condition across the sheath. Figures A-4 and A-5 clearly show, however, that although this case represents a valid MHD equilibrium solution, it is not a minimum-B solution. Local violations of minimum-B occur at two points along the inboard surface and at one point on the outboard surface. These violations are the result of oscillations in the signs of the six external pololdal field coll currents.

The sample case given in Figs. A-2 to A-5 is also an excellent example of the lack of control of the flux plume. From an engineering viewpoint, controlling the location of the flux plume is important because a reactor design must provide adequate room along the flux plume for a plasma dump. For this case space for a plasma dump was provided between the inboard and 46 


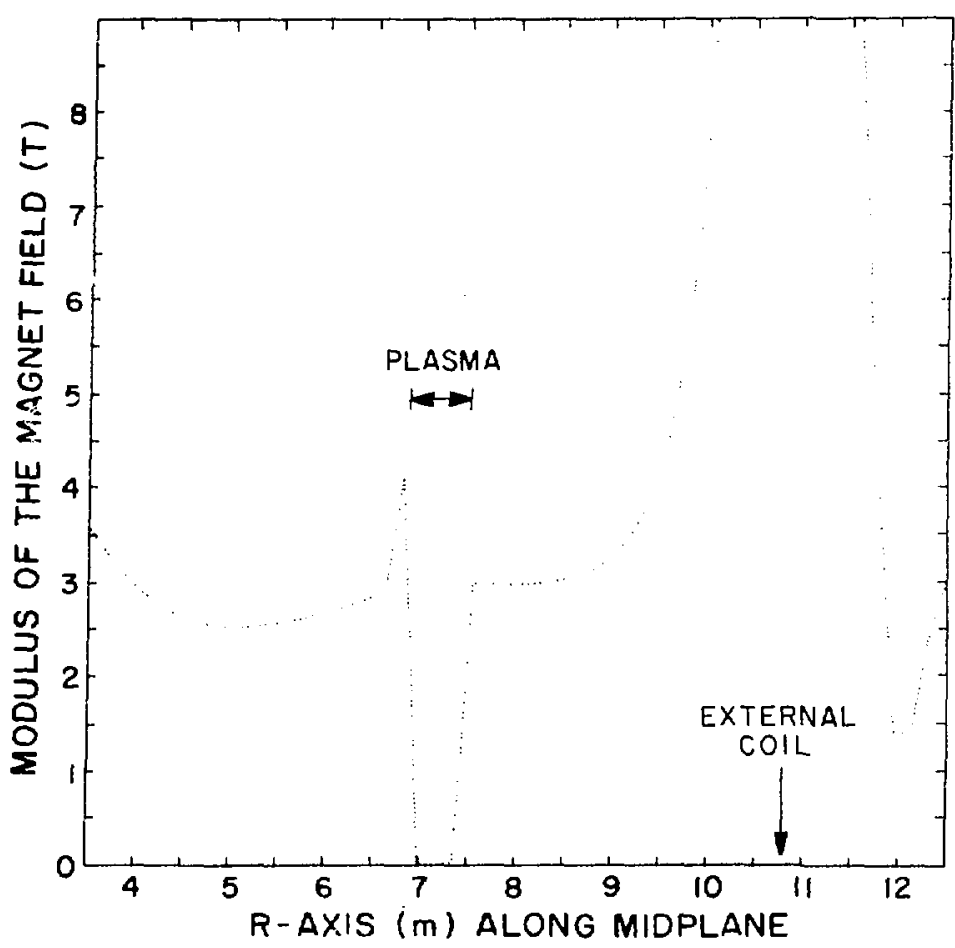
Fig. A-4. Variation in the modulus of the magnetic field (mod-B) along the
midplane for the case shown in Fig. A-2.

outboard pololdal field colls. The initial plasma shape had the flux plume pointed between the inboard and outboard poloidal field coils, i.e., the cusp point $\left(r_{c}, z_{c}\right)$ was $(9.25 \mathrm{~m}, 2.50 \mathrm{~m})$ and the inboard and outboard plasma surfaces intersected the mid-plane at $r=4.5 \mathrm{~m}$ and $8.0 \mathrm{~m}$, respectively. The code, however, pursued the solution of $\mathrm{Fig} \cdot \mathrm{A}-2$, whose flux plume runs between the two outermost poloidal field colls of the inboard set. Consequently, the initial plasma shape and pololdal field coil locations have a great, albeit unpredictable, effect on the final location of the flux plume.

By preventing the external coil currents from alternating in sign, (i.e., the inboard coll currents are of the opposite sign as the outboard coil currents) the likelihood that the equilibrium solution is also a minimum- $B$ solution is increased. Additionally, substantially more control of the flux plume location is afforded by this approach. These benefits, however, are attained at the cost of an increase in the error associated with the equilibrium fleld calculation. 


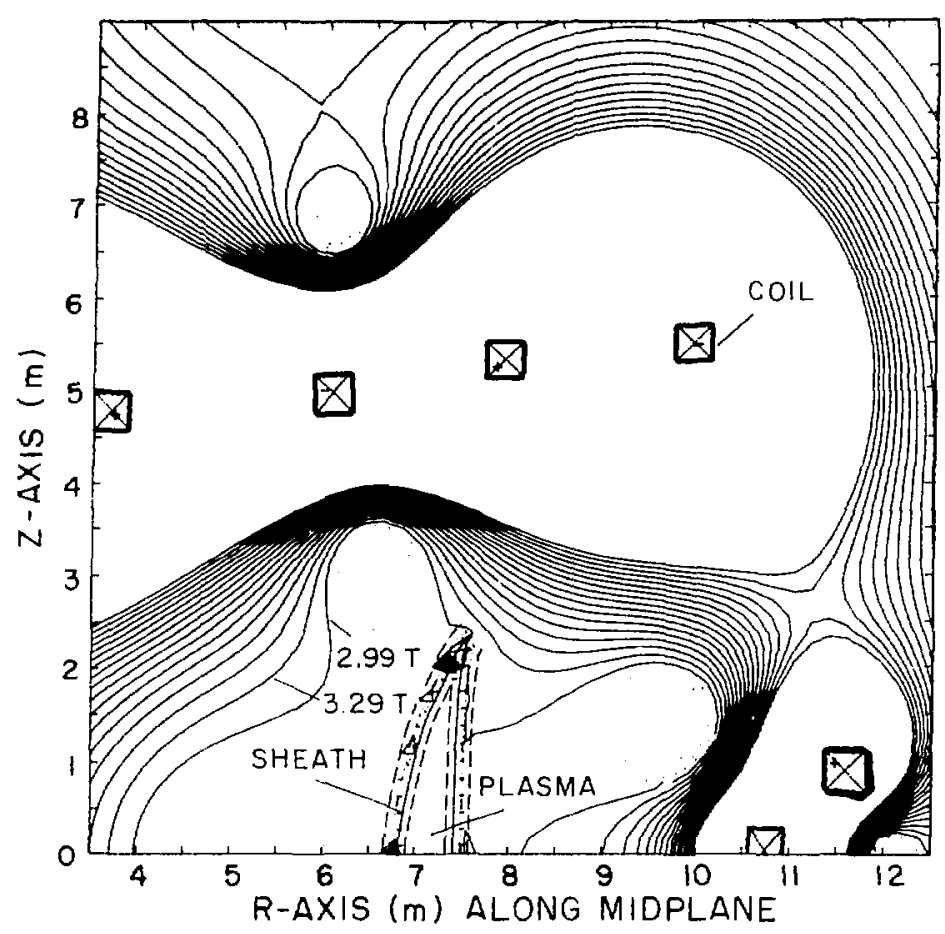

Fig. A-5. Mod-B contours for the same case given in Fig. A-2. Contour lines are incremented in steps of . 3T.

Adopting this approach is made difficult by the fact that the external PFC currents drop out of the flux Eqs. $(A-21)-(A-23)$. The approach can be implemented, however, by seeking for cases where the flux equations generate currents of the correct sign and subsequently imposing the condition that the signs are preserved while the plasma surface or external coil locations are allowed to move in search for an equilibrlum field. Such a starting point can usually be found by a trial and error process. :

The result of a calculation using this approach is presented in F1gs. A-6-A-7. A contour line of constant $B$ conforms to the plasma surface drawn as dotted IInes in Fig. A-6 to within $7 \%$ In B. At test surfaces drawn as dashed lines in Fig. A-6 located two coll spacings (2 $\Delta s$ ) outward from the plasma surface, the magnetic field is found to be higher than on the plasma surface, except for a small region on the inboard side (Fig. A-7). The region where mintmum-B is violated is approximately $12 \%$ of the distance along the Inboard surface between the mid-plane and the cusp. Considering that $N_{t}=4$ in $E q .(A-1)$ for this case, the surface is not sufficiently flexible to achieve the appropriate curvature on so small a scale. The amplitude of the 48 


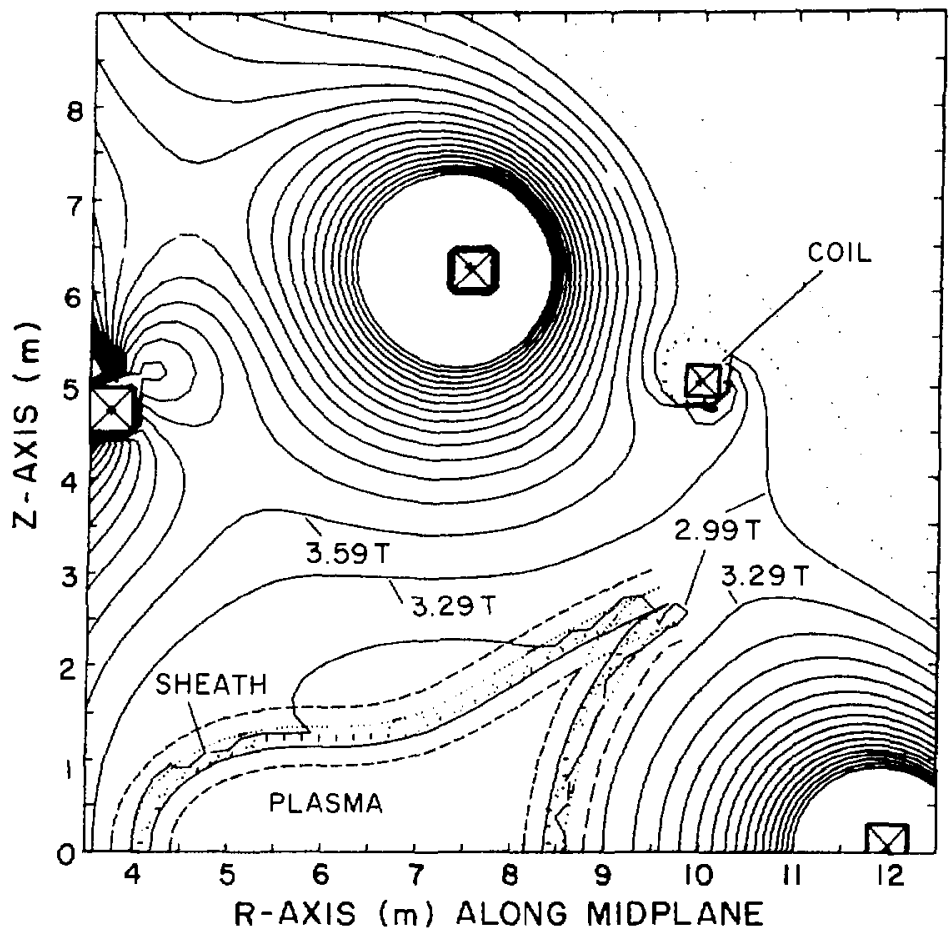

Fig. A-6. Mod-B contours for a $B=1$ equilibrium solution which is also a minimum-B solution. A dashed line represents an additional surface úsed in testing for minimum-B. Contour lines are incremented in steps of .3T.

error in the fleld along the surface is growing in this region, as is shown in Fig. A-7, which further compounds the problem. The higher mod-B contours, nevertheless, conform to the plasma surface, unlike the case of Figs. A-2-A-5. Consequently, this solution can be accepted as a minimum-B solution to within the accuracy of the numerical computation, although this solution is not a minimum-B solution in the strictest sense. The size of the region where minimum-B is violated can be reduced by raising the value of $N_{t}$, until a strictly minimum-B solution is obtained. Time limitations, however, prevented the determination of the $N_{t}$ value that will insure a strictly minimum- $B$ solution.

In the case of $B<1$ the concept of a minimum-B solution is not strictly applicable. The magnetic field on the outer plasma surface is seen to vary with I (Eqs. $(A-7)$ and $(A-9))$. Consequently, the best result that can be achieved corresponds to a "good curvature" solutioz; the magnetic field at any 


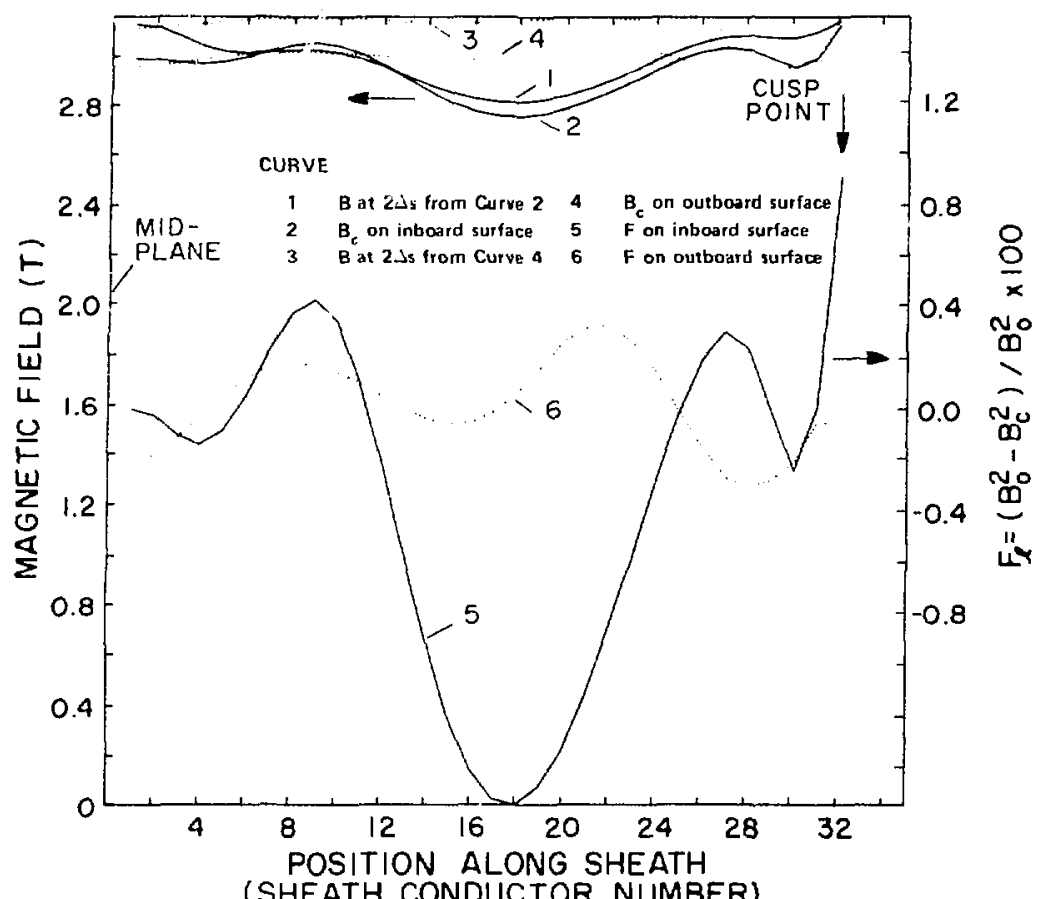

Fig. A-7. Plots of the lccal figure of merit, $F_{\ell}$, the magnetic field at the plasma surface, and the magnetic field at a test surface used to test for the minimum-B condition as a function of coil position along the surface.

point along the surface Increases along a normal to the surface and is pointed outward from the surface.

Establishing "good curvature" as a goal, a solution was sought that additionally met key engineering reactor constraints; the assurance of sufficient space for a blanket and shield between the external coils and the plasma appears as a crucial constraint. A blanket and shield was assumed to be accomodated by requiring that at least two meters exist between the external colls and the plasma surface. The detalls of the resulting equilibrium sclution are presented in Figs. A-8-A-12. The flux contours presented in Fig. 1-8 again demonstrate satisfactory compliance with the Tormac flux conditions. The vacuum first wall clearly should conform to one of the flux contour lines fust outside of the plasma. Figure A-9 shows the magnitude of the magnetic fleld along the midplane. The toroidal magnetic fleld is excluded from within the plasma only to the degree permitted by the beta value. The equilibrium fump conditions across the plasma surface are 


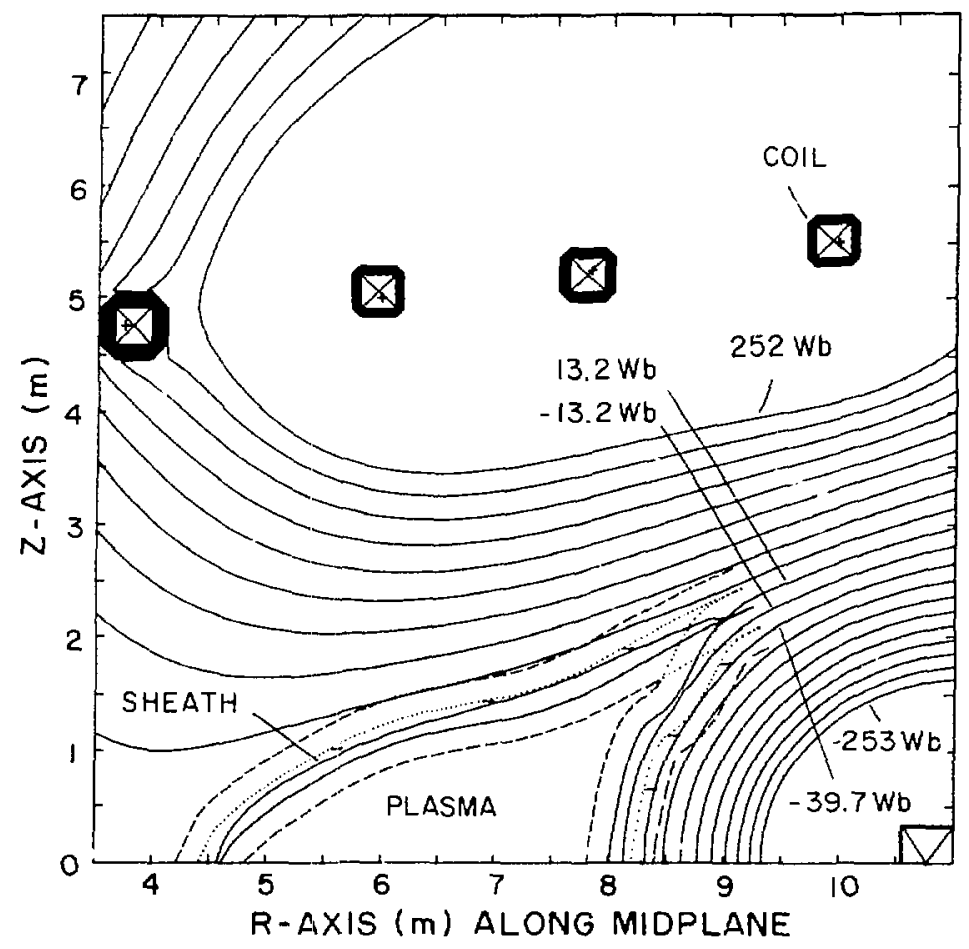

Fig. A-8. Flux contours for a $\beta \neq 1$ equilbrium solution with "good curvature". Contour lines are incremented in steps of $\sim 26.4 \mathrm{~Wb}$.

also seen to be met. Overlooking the spike in mod-B at the inboard plasma edge, which arises from the infinite field at a point current loop, this solution satisfies the "good curvature" criterion at the mid-plane. The question of "good curvature" can be investigated more fully with the mod-B plot of Fig. A-10. The magnetic field is seen to be increasing outwardly from the inboard plasma surface and also from the outboard plasma surface with the possible exception of an abnormality in the magnetic field about $2 / 3$ of the distance from the midplane to the cusp. A more detailed examination of the magnetic field on the outer plasma surface and at a test surface located two coll spacings (2 $\Delta s$ ) from the plasma surface, (Fig. A-11), however, reveals the inboard surface to meet marginally the "good curvature" criterion; the outboard surface meets the "good curvature" criterion by a wide margin despite the abnormality in the magnetic fleld.

The peculiar distortion of the outboard plasma surface gives rise to the abnormality. The procedure used to distribute the colls along the plasma surface has problems with the outboard surface. This procedural difficulty is 


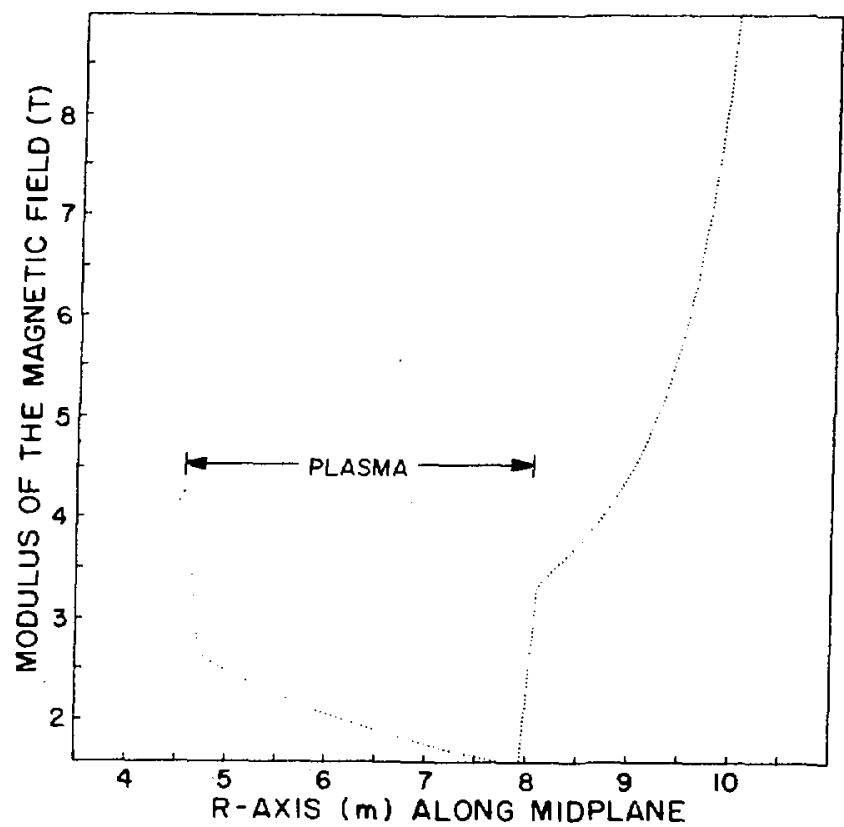

Fig. A-9. Mod-B along the midplane for the same case as in Fig. A-8. Spikes in field result from the presence of point loop currents.

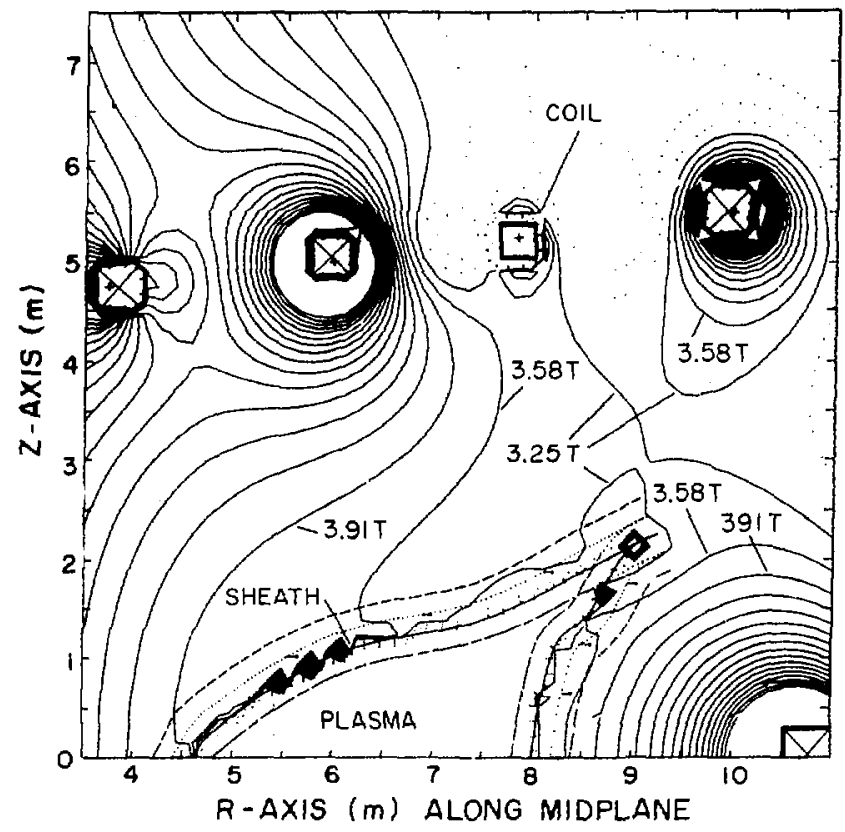

F1g. A-10. Mod-B contours for the same case as in Fig. A-8. Contour lines are incremented in steps of $.335 \mathrm{~T}$. 


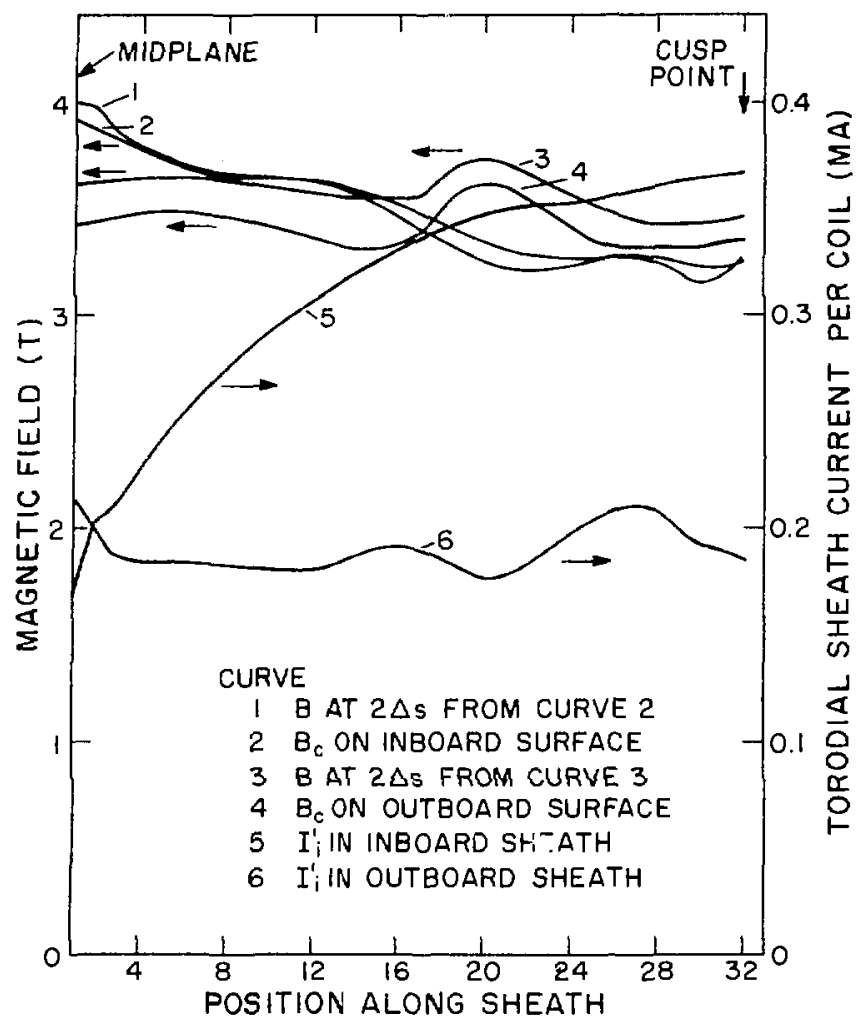

(SHEATH CONDUCTOR NUMBER)

Fig. A-11. Plots of the equilibrium sheath currents, the calculated equilibrium magnetic field, and the fleld on the surface for testing "good curvature" for the same case as in Fig. A-8 as a function of coil position a long the surface.

demonstrated in Fig. A-12 by the less uniform spacing of the sheath currents on the outboard surface than is attainable on the inboard surface. The equilibrium toroidal sheath currents shown in Fig. A-11 clearly reflect this problem and in turn propagate the error into the equilibrium field calculations, as demonstrated in Fig. A-12 by the plots of the local figure of merit, $F_{\ell}$, on the outer sheath surface.

Propagation of these kinds of errors complicates the process of seeking for "good curvature" solutions. Time limitations prevented dealing with this problem in any more depth than is presented here. For similar reasons an error analysis could not be completed.

obtaining "good curvature" $(\beta \neq 1)$ or mimimum- $B(\beta=1)$ is found to be more difficult on the inboard surface than the outboard surface because of curvature problems in addition to a greater inboard surface area and the 


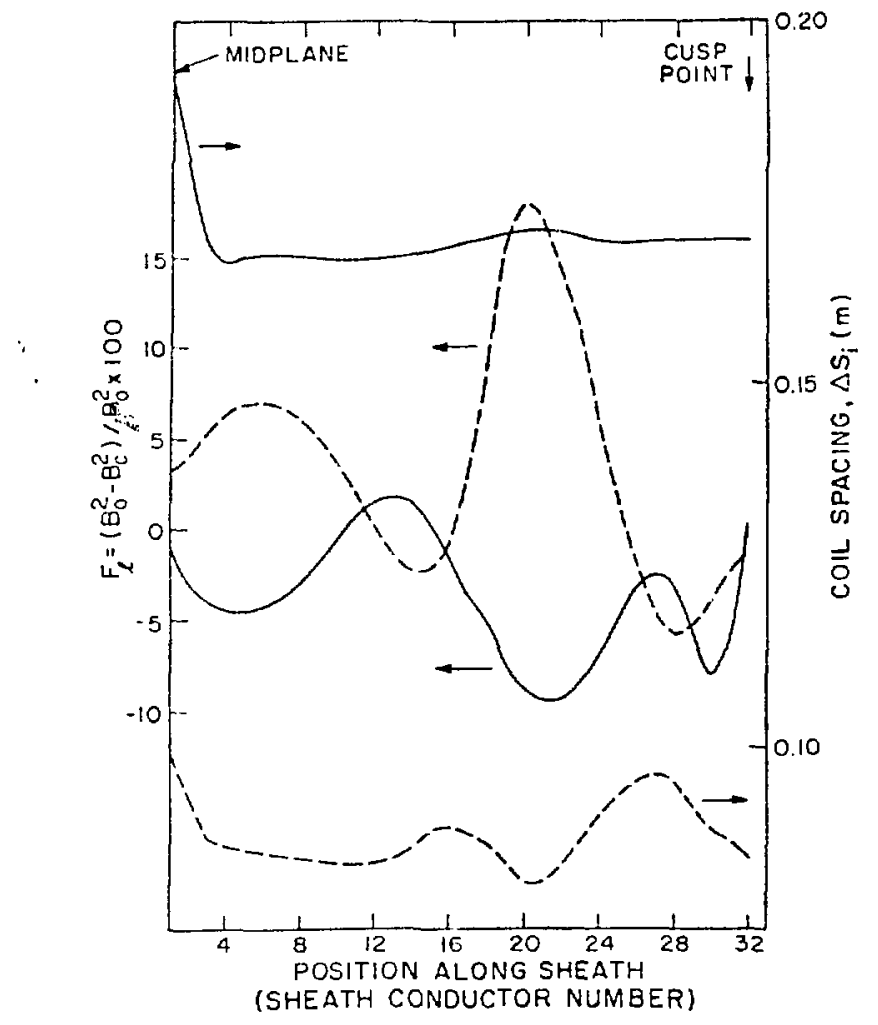

Fig. A-12. Plots of the coll spacing and 100 times the local figure of merit, $\mathrm{F}_{2}$, for the same case as in $\mathrm{Fig}$. A-8 as a function of coll position along the surface. The plotted values for the inboard and outboard surfaces are denoted by dashed and solid line, respectively.

resulting need for more poloidal field coils at these positions. In the $\beta \neq 1$ case, however, the field fluctuations on the inboard surface are smaller than the rate at which the equilibrium field is changing. Consequently, as demonstrated by Fig. A-12, the lower the beta the easier it is to find a "good curvature" solution.

D. Estimate of Tormac Reactor Configuration

The case presented in Figs. A-8 to A-12 is used as the basis of a representative Tormac reactor design appearing in Fig. 4. Key parameters that characterize the reactor are listed in Table A-I. With the appropriate scaling of only the magnetic fields and currents, this particular reactor may be transformed into Reactor $B$ of Table IV. The requirement that all external coils be at least 2 meters from the plasma in order to allow space for a blanket/shield adversely affects the TFC design. The distance from the center 
TABLE A-I

TORAMC REACTOR PARAMETERS DERIVED FROM MAGNETICS COMPUTATION

Parameter

average plasma minor radius, $r_{p}(m)$

average plasma major rádius, $R(m)$

aspect ratio, $A=R / r_{p}$

average beta, $\langle\beta\rangle$

distance to inner windings of the toroidal field coll, $h(m)$

peak torotdal field at $\operatorname{coll} \mathrm{B}_{\mathrm{c} \phi}(\mathrm{T})$

poloidal plasma sheath current, $I_{p}$ (MA)

average ion density, $\mathrm{n}\left(1 / \mathrm{m}^{3}\right)$

average ion temperature, $\mathrm{T}(\mathrm{keV})$
Value

1.12

7.61

6.8

0.77

2.0

8.35

21.83

$1.71(10)^{20}$

65

line to the instde edge of the TFC, $h$, is necessarily small, producing a large field at the coil and large Joule losses $\left(\sim 1 \times 10^{8}\right.$ Watts) in a normal copper coil. In order to be consistent with the reactor power-balance assumption of negligible Joule losses, superconducting coils would be required. The size depicted in the external colls depicted in Fig. 4 reflects the assumption that the TFC and PFC currents, that are summartzed in Table A-II for the five coils, flow at a current density of $12.5 \mathrm{MA} / \mathrm{m}^{2}$.

TABLE A-II

EXTERNAL POLODIAL FIELD COIL-LOCATIONS AND CURRENTS

(Refer to Fig. A-1)

Major Radius,
$\mathrm{R}(\mathrm{m})$

3.75

6.00

7.85

10.00

10.75

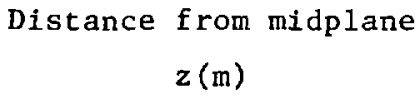

4.75

5.00

5.25

5.50

0.00

$$
\begin{gathered}
\text { Coil Current, } \\
I_{\mathbf{i}} \text { (MA) }
\end{gathered}
$$

7.813

19.925

4.443

11.472

$-29.093$ 
The distance between the coils and the plasma provides room for only $1.5 \mathrm{~m}$ thick blanket. The blanket is arranged in modular form for ease of malntenance. The wide gaps between the poloidal field coils are ideal for inserting structural support for the blanket and for handling and extracting the blanket modules. If auxiliary plasma heating, such as neutral beams, is required the external coll arrangement should provide for adequate access.

Space is provided for a plasma dump at the plasma cusp. Th1s high heat-flux facility would be analogous to the divertor of a tokamak but would possibly operate without divertor colls. Plasma that drifts along flux lines into the plasma dump would be eliminated from the reactor chamber by neutralizing the exhaust and then pumping it out of the system. The energy deposited is included as part of the thermal output of the reactor, although the thermal hydraulic difficulties incurred in handling the cusp power densities may not be any easier than those anticipated for tokamaks.

\section{REFERENCES}

1. H. Grad, "Motion and Stability of Free Surfaces," Conference on Thermonuclear Reactions, USAEC report WASH-289, 115-126, (June 1955).

2. J. Berkowitz, K. O. Friedrichs, H. Goertzel, H. Grad, J. Killeen, and E. Rubin, "Cusped Geometries," Proceedings of the Second United Nations International Conference on the Peaceful Uses of Atomic Energy, $\underline{31}$, $171-176$ (1958).

3. C. C. Gallagher, L. S. Combes, and M. A. Levin, "Plasma Behavior in a Toroidal High-B Device," The Physics of Fluids, 13, 1617-1625, (June 1970).

4. C. C. Gallagher and M. A. Levine, "Design and Construction of Tormac IV, a Toroidal, Bi-Cusp Plasma Containment Device," AFCRL-TR-74-0122, (6 March 1974).

5. M. A. Levine, I. G. Brown, and C. C. Gallagher, "Plasma Containment in a Toroida1 Bicusp (TORMAC), "Proceedings of the Third Topical Conference on Pulsed High Beta Plasmas, Pergamon Press, Oxford, 381-386, (1976).

6. M. A. Levine, A. H. Boozer, and W. B. Kunkel, "Tormac," Proceedings of the High Beta Workshop, Los Alamos Scientific Laboratory, ERDA-76/108, 298-334, (1976).

7. A. H. Boozer, "Toroldal Line Cusp Theory at Princeton," Proceedings of the Third Topical Conference on Pulsed High Beta Plasmas, Pergamon Press, Oxford, 387-390, (July 1975). 
8. M. A. Levine, I. G. Brown, and W. B. Kunkel, "Scaling for Tormac Fusion Reactors," Proceedings of the Second ANS Topical Meeting on the Technology of Controlled Nuclear Fusion, Richland, WA, CONF-760935, 353-358, (21-23 September 1976).

9. I. G. Brown, W. B. Kunkel, and M. A. Levine, "Tormac Reactor Considerations," Nuclear Fusion, 18, 761-768, (1978).

10. M. A. Levine, A. H. Boozer, G. Kalman, and P. Bakshi, "Particle Loss in a Toroldally Symmetric Cusp," Phystcal Review Letters, 28, 1323-1326, (15 May 1972).

11. A. H. Boozer and M. A. Levine, "Particle Trapping in Magnetic Line Cusps," Phystcal Review Letters, 31, 1287-1291, (19 November 1973).

12. R. A. Krakowsk1, R. L. M1ller, and R. L. Hagenson, "Preliminary Energy Balance Consideration for the Toroidal Magnetic (Bi-) Cusp: Tormac," Los Alamos Sclentific Laboratory report LA-UR-78-745 Rev., (1978).

13. R. A. Krakowsk1, R. L. Hagenson, R. L. Miller, and R. W. Moses, "Systems Studies and Conceptual Reactor Designs of Alternative Fusion Reactor Concepts at LASL," Proceedings of the Seventh International Conference on Plasma Physics and Controlled Nuclear Fusion Research, Innsbruck, Austria, IAEA-CN-37/I2, (August 1978), (in press).

14. "LASL Controlled Thermonuclear Research Program January-December 1978," Los Alamos Scientific Laboratory Progress Report, (in preparation).

15. J. W. Davis and G. L. Kulcinski, "Major Features of D-T Tokamak Fusion Reactor Systems," EPRI-472-1, (February 1976).

16. B. Badger, M. A. Abdou, R. W. Boom, R. G. Brown, T. E. Cheng, and R. W. Conn, "UWMAK-I, A Wiscons1n Toroldal Fusion Reactor Design," UWFDM-68, (15 March 1974).

17. B. Badger, R. W. Conn, G. L. Kulcinsk1, C. W. Maynard, R. Aronstein, and H. I. Avc1, "UWMAK-III, A Noncircular Tokamak Power Reactor Design," UWFDM-150, (July 1976).

18. R. W. Conn, G. L. Kulcinski, and C. W. Maynard, "NUWMAK: An Attractive Medium Field, Medium Size, Conceptual Tokamak Reactor," Proceedings of the Third ANS Topical Meeting on the Technology of Controlled Nuclear Fusion, Santa Fe, NM, CONF-780508, 1049-1069, (9-11 May 1978).

19. R. F. Bourque, "Parametric Requirements for Noncircular Tokamak Commerctal Fusion Plants," General Atomic Company report GA-A14876, (May 1978).

20. R. W. Mo1r, "Standard Mirror Fusion Reactor Design Study," Lawrence Livermore Laboratory report UCID-17644, (30 January 1978).

21. R. W. Moir, W. L. Barr, G. A. Carlson, W. L. Dexter, J. N. Doggett, and J. H. Fink, "Preliminary Design Study of the Tandem Mirror Reactor (TMR)," Lawrence Livermore Laboratory report UCRL-52302, (15 July 1977). 
22. R. T. Santoro and J. Mi. Barnes, "Nuclear Ferformance Calculations for the WMO Bumpy Torus Reactor (EETR) Reference Design," Oak Ridge liational Lahoratory repori ORNL/TM-60E5, (December 1977).

23. R. A. Krakowski, F. L. Ribe, T. A. Coultas, and A. J. Hatch, "An Enginecring? Lesion Study of a Reference Theta-Pinch Reactor (RTPR)," 1A-5336 and AKL-8019, (íarch 1974).

24. R. A. Krakowski, R. L. Miller, and K. L. lagenson, "Operating Point Considerations for the Reference Theta-Pinch Reactor (RTPR)," Proceedings of the Second Ais Topical iteeting on the Technology of Controlled Nuclear Fusion, Richtand, WA, COLF-760935, 359-370, (21-23 september 1976).

25. S. A. G. Gerstl, "A ininimun-Thickness Blanket/Shield with Optimun Iritiun breeding and Shielding iffectiveness," Proceedings of the Third his Topical heteing on the Technology of Controlled iuclear Fusion, Santa Fe, $\mathrm{NM}$, CONF-780508, 269-278, (9-11 liay 1978).

26. R. L. hatenson, R. A. Krakowski, and k. I. Thonassen, "A Toroidal Fusion Neactor liased on the Reversed-Field Pinch (RHP)," IAEA-TC-145, 337-355, (1978).

27. 2. L. Hagenson and R. A. Krakowski, and G. E. Cort, "The Reversed Field Pinch Reactor ( $\mathrm{KFPR}$ ) Concept," Los Alamos Scientific Laboratory report, to be putilished (1979).

28. $\mathrm{i}$. K. Fllis, "CIn dpplications of the High-Density Linear Theta Pinch," Nuclear Fusion, 15, 255-269, (1975).

20. R. L. Miller and R. A. Krakowski, "Fusion Reactor Plant Jesign for the Linenr Thetn-Dinch Peactor (ITPR)," Los Alamos Scientific Laboratory report iA-UM-78-2296, (1978).

30. I. Cr. P,ruwn and W. B. Eunkel, "Tormac Reactor Considerations," Lawrence Berkeley Laboratory report, LBL-6328, (July 1977).

31. D. J. Rose, M. Clark, Jr., Elasmas and Controlled Fusion, MIT Press, Cambridge, iass (1965).

32. L. Spitzer, Jr., Physics of Fully Ionized Gases, Interscience Publishers, Inc., New York (1956).

33. $\therefore$ A. Levine, "The Use of a lot Sheath Tornac for Advanced Fuels," Lawrence Lerkeley Laboratory report, LBL-6385 (July 1977).

34. U. A. Levine and $\mathrm{h}$. berk, persunal conmunication, LBL (1978).

35. A. H. Boozer, "Tormac Theory," personal comnunication, PPPL (1977).

36. H. Grad, "Boundary Layer Letween a Plasma and a lagnetic Field," The Fhysics of Fluids 4 , 1366-1375, (November 1961).

37. A. A. Nostrum and A. H. Poozer, "Annihilation liodel of the Tormac Sheath," Sherwood Theory lieeting, Gatlinburg, Tennessee (1978). 
38. S. Glasstone and R. H. Lovberg, Controlled Thermonuclear Reactions, Van Nostrand Reinhold Co., NY (1960).

39. R. F. Post, "High Temperature Plasma Research and Controlled Fusion," Annual Review of Nuclear Sclence, 9 , 367-436, (1959).

40. C. F. Wandel, T. H. Jensen, and O. Kofoed-Hansen, "A Compilation of Some Rates and Cross Sections of Interest in Controlled Thermonuclear Research," Nuclear Instruments and Methods, $4,249-260$, (1959).

41. K. S. Thomas and G. A. Sawyer, Eds., "LASL Controlled Thermonuclear Research Program January-December 1977," Los Alamos Scientific Laboratory Progress Report, LA-7474-PR, 151-152, (February 1979).

42. S. L. Greene, "Maxwell Averaged Cross Sections for Some Thermonuclear Reactions on Light Isotopes," Lawrence Livermore Laboratory report, UCRL-70522, (May 1967).

43. H. Dreicer, J. E. Hammel, J. Marshall, R. E. Siemon, and F. L. Ribe, "LASL Alternate Concept Evaluation," Los Alamos Sclentific Laboratory report LA-UR-76-2692, (1976).

44. F. F. Chen, "Alternate Concepts in Controlled Fusion," Electric Power Research Institute report EPRI-ER-429-SR, (May 1977).

45. J. F. Decker, Ed., "An Evaluation of Alternate Magnetic Fusion Concepts 1977," USDOE report DOE/ET-0047, (May 1978).

46. W. R. Smythe, Static and Dynamic Electricity, McGraw-Hill Book Co., NY 266, (1939).

47. R. Beckett and J. Hurt, Numerical Calculations and Algorithms, McGraw-H111 Book Co., NY, 269, (1967).

48. C. Bathke, "An Algorithm for Locating the Extremum of a Multi-Dimensional Constrained Function and Its Application to the PPPL Hybrid Study," Princeton Plasma Physics Laboratory report PPPL-1424, (March 1978). 